NELSON MARCOS FERRARI JUNIOR

\title{
Estudo epidemiológico descritivo dos doentes de melanoma cutâneo acompanhados na Unidade de Melanoma da Santa Casa de São Paulo
}

\author{
Dissertação apresentada à Faculdade de \\ Medicina da Universidade de São Paulo para \\ obtenção do título de Mestre em Ciências \\ Área de concentração: Dermatologia \\ Orientador: Dr. José Antonio Sanches Junior
}

São Paulo

2006 
AGRADECIMENTOS 
Ao Dr. José Antonio Sanches Junior, por me aceitar como orientando e pela orientação deste trabalho, sem a qual este não teria sido possível.

Ao Dr. Manoel Carlos S. de A. Ribeiro, pela análise estatística deste estudo.

Ao Dr. Marcus Maia, por ter permitido durante todos estes anos minha participação na Unidade de Melanoma da Santa Casa de São Paulo.

A todos os colegas da Clínica de Dermatologia do Departamento de Medicina da Santa Casa de São Paulo: a aqueles que me ensinaram a especialidade Dermatologia e em especial, a aqueles que me tornaram melhor ser humano e médico.

A Milena Weilan Pwa, minha esposa, por sua dedicação, compreensão e companheirismo. 
SUMÁRIO 


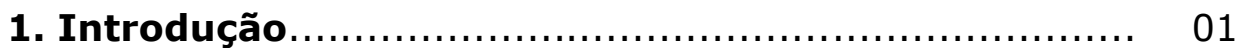

1.1. Objetivos......................................... 05

2. Revisão da literatura ................................... 06

2.1.Dados demográficos e clínicos........................ 07

2.1.1. Sexo........................................ 07

2.1.2. Idade.......................................... 09

2.1.3. Cor....................................... 10

2.1.4. Localização da lesão primária................. 12

2.1.5. Tipo de crescimento.......................... 14

2.2. Dados histopatológicos............................... 18

2.2.1. Espessura tumoral.......................... 18

2.2.2. Presença de ulceração......................... 20

2.2.3. Nível de Clark.................................. 21

3. Casuística e métodos................................... 23

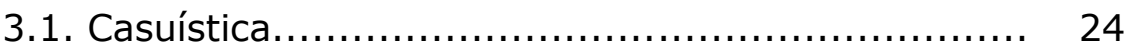

3.2. Métodos......................................... 25

3.2.1. Critérios de inclusão.............................. 25

3.2.2. Critérios de avaliação das variáveis........... 27

3.2.3. Análise estatística........................... 29

4. Resultados............................................... 30

4.1. Descrição quanto ao estadiamento................... 31

4.2. Descrição das variáveis demográficas e clínicas...... 34

4.2.1. Distribuição quanto ao sexo................... 34

4.2.2. Distribuição quanto à idade.................... 35

4.2.3. Distribuição quanto à cor...................... 35

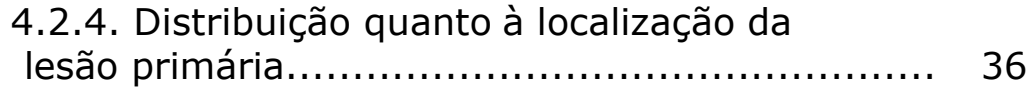

4.2.5. Distribuição quanto ao tipo de crescimento.. 36

4.3. Descrição quanto às variáveis histológicas............. 37

4.3.1. Distribuição quanto à espessura tumoral..... 37

4.3.2. Distribuição quanto aos níveis de Clark...... 38

4.3.3. Distribuição quanto à presença de ulceração. 38

4.4. Correlação entre as variáveis............................ 39

4.4.1. Sexo e idade................................. 39

4.4.2. Sexo e localização da lesão primária........... 40

4.4.3. Sexo e tipo de crescimento..................... 40

4.4.4. Sexo e espessura tumoral........................ 41

4.4.5. Sexo e presença de ulceração.................. 41

4.4.6. Idade e localização da lesão primária.......... 42

4.4.7. Idade e tipo de crescimento.................... 43

4.4.8. Idade e espessura tumoral.................... 44

4.4.9. Idade e presença de ulceração.................. 44 
4.4.10. Cor e localização da lesão primária.......... 45

4.4.11. Cor e tipo de crescimento.................... 46

4.4.12. Espessura tumoral e tipo de crescimento.. 47

4.5. Evolução dos pacientes............................... 48

4.6. Sobrevida média e taxa de sobrevida................. 50

4.7. Letalidade............................................ 50

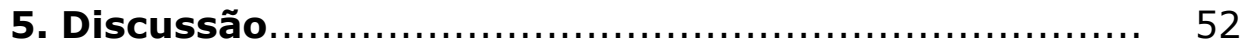

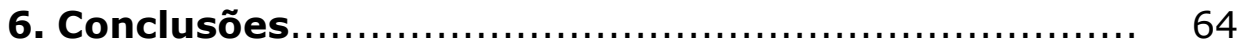

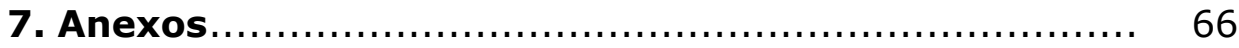

8. Revisão bibliográfica...................................... 83

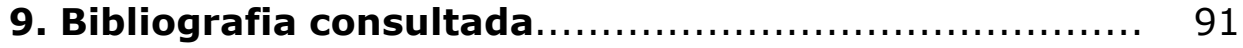


LISTA DE QUADROS, TABELAS, GRÁFICO E ORGANOGRAMA 
Quadro 1- Dados dos autores nacionais da região sul quanto à cor, ao sexo, à idade, à localização da lesão primária e ao tipo de crescimento do melanoma cutâneo em suas casuísticas .............. 17

Quadro 2- Dados dos autores nacionais nas outras regiões, quanto à cor, ao sexo, à localização da lesão primária e ao tipo de crescimento do melanoma cutâneo em suas casuísticas.

Quadro 3- Espessura média de Breslow em milímetros de acordo com os seguintes autores, por local de origem e ano de publicação. 20

Tabela 1- Distribuição de 364 casos de melanoma cutâneo conforme a apresentação clínica no momento da entrada do paciente no protocolo-UMSC-SP 1993-2006.

Tabela 2- Distribuição de 332 casos de melanoma cutâneo quanto à invasão do tumor primário na UMSC-SP 1993-2006.

Tabela 3- Distribuição de 269 casos de melanoma cutâneo invasivos quanto ao microestadiamento da lesão primária, onde "a" representa os tumores sem ulceração e "b" aqueles com ulceração para qualquer pT e com ulceração ou nível de Clark IV ou V para pT1, na UMSC-SP 1993-2006.

Tabela 4- Distribuição de 251 casos de melanoma cutâneo categorizados quanto à presença de doença linfonodal na UMSC-SP 1993-2006.

Tabela 5- Distribuição de 223 casos de melanoma cutâneo categorizados quanto à presença de doença metastática na UMSC-SP 1993-2006

Tabela 6- Distribuição de 354 casos de melanoma cutâneo quanto ao estadiamento clínico na UMSC-SP 1993-2006.

Tabela 7- Distribuição de 364 casos de melanoma cutâneo quanto ao sexo na UMSC-SP 1993-2006.

Tabela 8- Distribuição de 250 casos de melanoma cutâneo com doença localizada, quanto à idade, em intervalos de 20 anos na UMSC-SP 1993-2006 
Tabela 9- Distribuição de 364 casos de melanoma cutâneo quanto à cor dos pacientes na UMSC-SP 1993-2006

Tabela 10- Distribuição de 364 casos de melanoma cutâneo quanto à localização da lesão primária na UMSC-SP 1993-2006

Tabela 11- Distribuição de 364 casos de melanoma cutâneo quanto ao tipo de crescimento na UMSC-SP 1993-2006

Tabela 12- Distribuição de 332 casos de melanoma cutâneo quanto à espessura de Breslow na UMSC-SP 1993-2006

Tabela 13- Distribuição de 332 casos de melanoma cutâneo quanto aos níveis de Clark na UMSC-SP 1993-2006 38

Tabela 14- Distribuição de 270 casos de melanoma cutâneo invasivo quanto à presença de ulceração na UMSC-SP 1993-2006. 38

Gráfico 1- Distribuição de 250 casos de melanoma cutâneo conforme a idade e o sexo dos pacientes, em intervalos de dez anos, na UMSCSP 1993-2006 39

Tabela 15- Distribuição de 352 casos de melanoma cutâneo quanto ao sexo em relação à localização da lesão primária na UMSC-SP 1993-2006. 40

Tabela 16- Distribuição de 364 casos de melanoma cutâneo quanto ao sexo em relação aos tipos de crescimento na UMSC-SP 19932006.

Tabela 17- Distribuição de 274 casos de melanoma cutâneo quanto ao sexo em relação à espessura de Breslow na UMSC-SP 19932006 41

Tabela 18- Distribuição de 325 casos de melanoma cutâneo quanto ao sexo em relação à presença de ulceração na UMSC-SP 19932006

Tabela 19- Distribuição de 249 casos com melanoma cutâneo quanto à idade em relação à localização da lesão primária na UMSCSP 1993-2006. 
Tabela 20- Distribuição de 250 casos com melanoma cutâneo quanto à idade em relação ao tipo de crescimento na UMSC-SP 19932006

Tabela 21- Distribuição de 194 pacientes com melanoma cutâneo quanto à idade e a espessura de Breslow na UMSC-SP 19932006.

Tabela 22- Distribuição de 250 casos com melanoma cutâneo quanto à idade em relação à presença de ulceração na UMSC-SP 1993-2006.

Tabela 23- Distribuição de 353 casos com melanoma cutâneo quanto à cor dos pacientes em relação à localização da lesão primária na UMSC-SP 1993-2006.

Tabela 24- Distribuição de 364 casos de melanoma cutâneo quanto à cor dos pacientes em relação ao tipo de crescimento na UMSC-SP 1993-2006 46

Tabela 25- Distribuição de 82 casos de melanoma acrolentiginoso quanto à localização da lesão primária nos pacientes brancos e nãobrancos na UMSC-SP 1993-2006.

Tabela 26- Distribuição de 265 casos de melanoma cutâneo quanto à espessura de Breslow em relação ao tipo de crescimento na UMSCSP 1993-2006.

Organograma 1- Evolução dos pacientes com MC conforme seu estadiamento inicial, na UMSC-SP 1993-2006...

Tabela 27- Distribuição de 357 casos de óbito em relação ao estadiamento inicial dos pacientes com melanoma cutâneo na UMSCSP 1993-2006.

Tabela 28- Índices percentuais relativos ao número de óbitos nos intervalos das espessuras de Breslow de 269 casos de melanoma cutâneo na UMSC-SP 1993-2006. 51 
RESUMO 
Ferrari Junior, N.M. Estudo epidemiológico descritivo dos doentes de melanoma cutâneo acompanhados na Unidade de Melanoma da Santa Casa de São Paulo [dissertação]. São Paulo: Faculdade de Medicina, Universidade de São Paulo; 2006. 92p.

INTRODUÇÃO: O melanoma cutâneo constitui cerca de $3 \%$ de todos os tumores da pele. Atinge indivíduos jovens com média de idade de aparecimento entre 50 e 58 anos. Em torno de $20 \%$ dos doentes apresentarão doença avançada e morrerão antes de completar cinco anos de sobrevida. CASUÍSTICA E MÉTODOS: Neste estudo retrospectivo de 364 casos acompanhados de maio de 1993 a janeiro de 2006 descreveram-se as variáveis: sexo, idade, cor, localização da lesão primária, tipo de crescimento, espessura de Breslow, nível de Clark, presença de ulceração, estadiamento e suas correlações. RESULTADOS: Predominou o sexo feminino (58,8\%) resultando em uma proporção de 1,4 mulheres para cada homem. A média das idades dos pacientes foi de 58,9 anos e a mediana de 61,0 anos. Pacientes não-brancos constituíram $13,7 \%$ da amostra. Para homens e mulheres o melanoma cutâneo localizou-se, predominantemente no tronco $(24,3-38,0 \%)$ e pés $(21,4-23,9 \%)$. O melanoma acrolentiginoso representou $22,3 \%$ de toda amostra. Os padrões melanoma expansivo superficial e melanoma nodular $(p<0,001)$ e lesões no tronco $(52,8 \%)$ predominaram nos indivíduos brancos. O melanoma acrolentiginoso (64\%) e a localização nos pés $(68,2 \%)$ prevaleceram nos pacientes não-brancos. Observou-se minoria de casos com lesão primária in situ $(14,6 \%$ - EC 0$)$ e alto percentual de melanoma cutâneo espesso $(39,7 \%>4,0 \mathrm{~mm})$. Presença de ulceração foi observada em $13,4 \%$ para tumores finos $(=1,0 \mathrm{~mm})$. Homens apresentaram lesões mais espessas $(p=0,011)$ e ulceradas $(p<0,001)$ em relação às mulheres, assim como idosos em relação à não idosos ( $p=0,021$ para a espessura e $p=0,015$ para ulceração). A sobrevida média para os pacientes com doença localizada foi de 97,8 meses e a taxa de sobrevida específica para melanoma cutâneo foi de $85,1 \%$ em três anos. CONCLUSÕES: Esta amostra constituiu-se de pacientes com tumores espessos e ulcerados denotando diagnóstico tardio do melanoma cutâneo e pior prognóstico. Caracterizou-se por apresentar predomínio de mulheres, de pacientes não-brancos, de lesões nas extremidades e de melanoma acrolentiginoso.

Descritores: neoplasias cutâneas, melanoma, epidemiologia, estudos retrospectivos, distribuição por sexo, mulheres, distribuição por idade, extremidades, taxa de sobrevivência. 
SUMMARY 
Ferrari Junior, N. M. Descriptive epidemiological study in cutaneous melanoma patients followed at Melanoma Unit of Santa Casa de São Paulo. [dissertation] São Paulo: Faculdade de Medicina, Universidade de São Paulo; 2006. 92p

INTRODUCTION: Cutaneous melanoma represents around 3\% of all skin tumors. Affecting young patients, with mean age between 50 and 58 years old. About $20 \%$ of the patients will have advanced disease and will die before five years of survival. CASUISTIC AND METHODS: In this retrospective study of 364 cases recorded from May 1993 to January 2006 at the Melanoma Unit of Santa Casa de São Paulo the following variables were described: sex, age, skin color, tumor site, growth pattern, tumor thickness, Clark level, ulceration, staging and their correlations. RESULTS: Female $(58,8 \%)$ prevailed resulting in 1,4 women for each man. The mean age of the patients was 58,9 years old and the median, 61,0 years old. Non-white patients were $13,7 \%$ of the sample. The anatomic site of cutaneous melanoma on men and women prevailed at trunk $(24,3-38,0 \%)$ and feet $(21,4-$ $23,9 \%)$. Acral lentiginous melanoma represented $22,3 \%$ of the cohort. Superficial expansive melanoma and nodular melanoma patterns $(p<0,001)$ and trunk lesions $(52,8 \%)$ predominated on white patients. Acral lentiginous melanoma (64\%) and feet anatomic site $(68,2 \%)$ prevailed on non-white patients. In situ primary lesions were observed in few cases $(14,6 \%$ - EC 0$)$ and there was high percentage of thick cutaneous melanoma $(39,7 \%>4,0 \mathrm{~mm})$. In thin tumors $(=$ $1,0 \mathrm{~mm})$ were found $13,4 \%$ of ulceration. Thickener $(p=0,011)$ and ulcerated lesions $(p<0,001)$ were found more in male and in elderly patients ( $p=0,021$ for thickeness and $p=0,015$ for ulceration). The mean survival of patients with local disease was 97,8 months and the three-year survival rate for cutaneous melanoma was $85,1 \%$. CONCLUSIONS: The cohort consisted mostly of thick and ulcerated tumors, which meant late diagnosis and bad prognosis. Also distinguished by considerable prevalence of female, non-white patients, limb lesions and acral lentiginous melanoma.

Descriptors: skin neoplasms, melanoma, epidemiology, retrospectives studies, sex distribution, women, age distribution, extremities, survival rate. 
INTRODUÇÃO 
Durante a segunda metade do século passado, os cânceres da pele aumentaram em incidência e mortalidade. A razão para este aumento relaciona-se, provavelmente, com as mudanças de hábito das pessoas, tanto nas formas de lazer quanto nos tipos de vestimenta. Dentre eles, o melanoma cutâneo (MC), foco deste estudo, apesar de contribuir com apenas 3\% de todos os tumores da pele apresenta morbidade significativa e alto índice de mortalidade.

O MC representa $75 \%$ de todas as mortes por neoplasias malignas cutâneas e um a $2 \%$ de todas as mortes por câncer nos EUA, constituindo-se assim, problema de saúde pública preocupante e dispendioso (Parker et al., 1996). Entre os pacientes diagnosticados com MC, em torno de $20 \%$ terão doença avançada e conseqüentemente morrerão antes de completar cinco anos de sobrevida (Mackie et al., 1995).

Diferente de outros tipos de câncer, o MC freqüentemente atinge indivíduos jovens, com média de idade de aparecimento em torno dos cinqüenta anos. Por esta razão o MC está entre os cânceres 
com maior média de anos de vida perdidos por pessoa. Como agravante e a despeito de todos os esforços realizados, as terapias utilizadas em casos avançados tais como: quimioterapia, radioterapia, bioterapia e vacinas têm se mostrado incapaz de curar bem como de melhorar seus índices de sobrevida.

De acordo com os dados do Surveillance, Epidemiology, and End Results (SEER) para o ano de 2002, o MC foi o quinto câncer mais freqüente em homens e o sexto entre mulheres considerando-se os casos novos de câncer nos EUA. Em Queensland, Austrália, onde se encontra a maior incidência mundial de MC, a taxa de incidência para homens dobrou entre 1979 e 1987, atingindo 55,8 casos para cada 100.000 habitantes e entre mulheres atingiu 42,9 por 100.000 (Barth et al., 1995).

O conhecimento das características epidemiológicas do MC, tanto clínicas como histológicas contribui para o melhor entendimento desta doença facilitando a ação médica na identificação dos casos, assim como no planejamento das campanhas direcionadas à comunidade médica como à população a ser atingida.

A primeira avaliação de múltiplos fatores epidemiológicos e prognósticos em relação ao $M C$, cujos pacientes provinham de uma única instituição, foi publicada por Balch et al. em 1978 e a primeira 
proveniente de várias instituições ocorreu com o estudo de van der Esch et al. em 1981.

No Brasil não existem estudos populacionais sobre o $\mathrm{MC}$ e a literatura mostra casuísticas hospitalares isoladas e incompletas, o que pode não refletir dados epidemiológicos locais. Além disso, o Brasil é país de dimensão continental com composição étnica variada conforme a localização geográfica, que provavelmente modifica as características epidemiológicas do MC de acordo com cada região.

A criação do Grupo Brasileiro de Melanoma (GBM) em 1995 e a implantação de protocolo completo de coleta de dados nacionais, preenchidos via Internet, possibilitarão em futuro próximo traçar perfil abrangente do MC no país. Casuísticas institucionais criteriosas, com significativo número de casos, começam a surgir no Brasil. Este fato não apenas possibilitará a "alimentação" do banco de dados do GBM, como permitirá investigação básica e aplicada nesta doença.

A partir do ano de 1993, com a criação da Unidade de Melanoma Cutâneo da Santa Casa de São Paulo (UMSC-SP), os pacientes com diagnóstico de MC admitidos no Serviço de Dermatologia do Departamento de Medicina da Faculdade de Ciências Médicas da Santa Casa de Misericórdia de São Paulo passaram a ser protocolados em questionário informatizado. Isto vem contribuindo 
para a constituição de uma coorte, com dados suficientes para estudos epidemiológicos e clínicos dentro desta instituição. Embora estes dados possam não ser representativo do que ocorre em todo Brasil, certamente contribui com informações auxiliares para a comunidade científica envolvida no diagnóstico, tratamento e condução desta enfermidade.

\subsection{Objetivos}

Este trabalho analisa dados clínicos e histopatológicos da casuística da UMSC-SP com os seguintes objetivos:

1- Conhecimento do comportamento da população estudada em relação às variáveis demográficas: sexo, idade, cor, variáveis clínico-patológicas: localização da lesão primária, tipo de crescimento, espessura de Breslow, nível de Clark, presença de ulceração e quanto ao estadiamento proposto pela American Joint Committee on Cancer (AJCC) de 2002.

2- Estudar as relações entre as variáveis acima. 
REVISÃO DA LITERATURA 


\subsection{Dados demográficos e clínicos}

\subsubsection{Sexo}

As taxas de incidência padronizadas para idade para o MC demonstram distribuição semelhante entre os sexos, com discreta predominância em homens na Austrália, Nova Zelândia, EUA (1,4: 1) e em mulheres no norte e oeste da Europa $(1,4: 1)$. A maior predominância em mulheres encontra-se na África oriental $(1,9: 1)$ (Parkin et al., 2005) e há relato de predomínio em mulheres em regiões de menor insolação e baixa incidência de $M C$ (Weinstock e Mikkilinemi, 2001). Embora a incidência na Austrália seja maior em homens (1,3: 1$)$, o seu aumento encontra-se estabilizado, com declínio entre mulheres (Marrett et al., 2001).

Nos EUA, a predominância para o sexo masculino é semelhante à australiana. Comparando os períodos de 1974-1975 e 1988-1989 as incidências de MC aumentaram para ambos os sexos, com exceção do sub grupo de mulheres com doença localizada. 
Comparando os anos de 1988 e 1997 houve aumento em homens tanto com doença localizada quanto loco-regional, mas não entre as mulheres (Jemal et al., 2001).

No Brasil não existem dados de incidência com base populacional. É importante ressaltar que os estudos brasileiros baseiam-se em casuísticas institucionais isoladas.

Especificamente na região sul encontra-se a maioria dos trabalhos demonstrando predomínio do sexo feminino, com percentuais variando entre $53,1 \%$ a $66,9 \%$ (Bakos, 1991 ; Bernardi et al., 1998; Gon et al., 2001; Bakos et al., 2002; Moreno, 2005). Apenas dois autores apresentam relatos de predomínio do sexo masculino (Minelli e Pereira, 1983; Venegas et al., 1992) e um autor refere distribuição igual entre os sexos (Nasser, 1993) (Quadro 1 ).

Para outras regiões brasileiras a maioria dos autores também demonstra predomínio do sexo feminino (Lucas et al., 1994; Fernandes et al., 1996; Giavina-Bianchi et al., 1996; Criado et al., 1999; Lapa et al., 2002; Pinheiro et al., 2003). São poucos os relatos com predomínio do sexo masculino ou igualdade entre os sexos (Bandiera e Prudente, 1967; Brandão et al., 1998; Fernandes et al., 2005) (Quadro 2). 


\subsubsection{Idade}

O MC é um tumor que acomete principalmente adultos jovens e idosos com média de idade de aparecimento entre 50 e 58 anos. (Weinstock e Berwick, 2003). A taxa de incidência específica para as faixas etárias nos EUA apresenta discreto aumento em homens com idade acima de 45 anos (SEER, 2002). Conforme o Australian Institute of Health and Welfare (AIHW) e o Australasian Association of Cancer Registries (AACR), em 2000, o aumento da incidência desde 1982 de MC esta restrita aos indivíduos com idade até 60 anos. Estas informações sugerem que a exposição solar tenha diminuído ou estabilizado nos últimos anos, já que, acredita-se que a exposição solar na infância é fator fundamental para o desencadeamento da doença.

No Brasil, na região sul, encontra-se predomínio do MC na faixa etária de 36-60 anos (Minelli e Pereira, 1983; Dick et al., 1989; Venegas et al., 1992). Outros trabalhos demonstram predomínio de MC em faixa etária mais avançada, entre 60-70 anos (Bakos, 1991; Nasser, 1993; Bernardi et al., 1998) (Quadro 1 ).

Quanto à média das idades no momento do diagnóstico, nos estudos brasileiros, encontram-se valores entre 46,1 a 47,8 anos (Venegas et al., 1992; Moreno, 2005), dados abaixo das médias 
mundiais e valores entre 52,8 e 56,4 anos (Gon et al., 2001; Bakos et al., 2002), dados comparáveis com as referências mundiais acima citadas (Quadro 1 ).

Para as outras regiões brasileiras observam-se faixas etárias predominantes entre 40 e 60 anos (Bandiera e Prudente, 1967; Fernandes et al., 1996; Criado et al., 1999; Lapa et al., 2002) e entre 60 e 80 anos, (Giavina -Bianchi et al., 1996; De Donato et al., 1997; Fernandes et al., 2005) (Quadro 2).

Um único trabalho brasileiro (Brandão et al., 1998) calcula a média das idades (51,2 anos) semelhante à encontrada pelos autores da região sul do país e aos relatos internacionais.

\subsubsection{Cor}

O MC varia nas suas características epidemiológicas e clínicas nas diferentes regiões geográficas e uma das possíveis explicações para isto é a composição étnica dos povos. Caracteristicamente é um câncer que predomina em indivíduos de cor branca. Raro em asiáticos, onde a incidência é menor de um caso para 100.000 habitantes por ano, é freqüente em europeus onde a incidência varia entre dois e 15 casos por 100.000 habitantes e na Austrália, local 
onde a incidência é a maior do mundo, 40 casos para cada 100.000 habitantes (International Union Against Cancer (UICC), 1997).

Nos EUA a incidência de MC em indivíduos brancos é dez a vinte vezes maior do que em pacientes não-brancos vivendo em uma mesma localidade com taxas de 14,8 por 100.000 habitantes por ano para brancos e 0,9 por 100.000 para não-brancos (SEER, 2002).

Mesmo para pacientes brancos temos variabilidade na incidência de MC. Na Califórnia, Novo México, é três a quatro vezes maior entre brancos não hispânicos do que em hispânicos. Também na Europa encontram-se diferenças, onde as taxas são altas em paises nórdicos e baixas em países do sul da Europa (UICC, 1997).

No Brasil, na região sul, onde o predomínio populacional é de indivíduos da cor branca, a unanimidade dos autores apresenta casuísticas do MC, com quase a totalidade de pacientes brancos, variando entre $96,6 \%$ a $100 \%$ (Minelli e Pereira, 1983 ; Venegas et al., 1992; Bakos et al., 2002) (Quadro 1 ).

Nas outras regiões, observa-se predomínio de MC em pacientes brancos, porém o acometimento de não-brancos é considerável, variando entre $6 \%$ a $17,1 \%$ (Bandiera e Prudente, 1967; Fernandes et al, 1996; Brandão et al., 1998; Lapa et al., 2002; Pinheiro et al., 2003) (Quadro 2 ). 


\subsubsection{Localização da lesão primária}

Em indivíduos brancos as localizações preferenciais são membros inferiores e dorso para mulheres e dorso para os homens, enquanto que, em não-brancos as localizações preferenciais são região plantar, região palmar, leito ungueal e mucosas (Sober e Tsao, 2003).

Quanto à incidência do MC nas diferentes localizações da lesão primária, na Austrália, demonstra-se grande aumento da incidência de MC localizado no tronco e membros superiores e pequeno aumento de tumores na cabeça e pescoço (Armstrong e Kricker, 1994; Giles et al., 1996).

No Canadá no período de 1969 a 1993 também se encontra um grande aumento de tumores nos membros superiores seguidos dos tumores no tronco para ambos os sexos (Bulliard et al., 1999). Na Nova Zelândia, para o mesmo período, relata-se aumento de MC nos membros superiores para os homens e no tronco para as mulheres (Bulliard e Cox, 2000). Nos EUA relata-se que os locais mais afetados para homens são tronco e cabeça, sendo incomum nas pernas. Para mulheres, pernas e tronco são igualmente acometidos (Weinstock e Mikkilinemi, 2001). 
Quanto à localização da lesão primária, na região sul do Brasil encontra-se uniformidade dos achados, com predomínio de MC nos membros em torno de $42 \%$ dos casos seguidos do tronco em torno de $35 \%$ e menos incidentes na cabeça e pescoço, em torno de 23\% dos casos (Minelli e Pereira, 1983; Venegas et al., 1992; Bernardi et al., 1998; Bakos et al., 2002; Moreno, 2005) (Quadro 1 ).

Quanto à relação da localização da lesão primária com o sexo observa-se predomínio de MC no tronco de pacientes homens e nos membros, especialmente membros inferiores, de mulheres (Venegas et al., 1992; Bernardi et al., 1998; Gon et al., 2001).

Nas outras regiões do Brasil observa-se também uniformidade dos achados, com ocorrência de MC localizados principalmente nos membros, de 39 a 66\% (Bandiera e Prudente, 1967; Fernandes et al., 1996; Giavina-Bianchi et al., 1996; De Donato et al., 1997; Lapa et al., 2002; Pinheiro et al., 2003) (Quadro 2).

Quanto à relação da localização da lesão primária e o sexo dos pacientes encontra-se predomínio da localização no dorso para os homens, com $29,4 \%$ dos casos e nos membros inferiores para as mulheres, com 38,3\% dos casos (Criado et al., 1999) (Quadro 2 ). 


\subsubsection{Tipo de crescimento}

Os quatro principais padrões de crescimento do MC são lentigo maligno melanoma (LMM), melanoma expansivo superficial (MES), melanoma nodular (MN) e melanoma acrolentiginoso (MAL) que inclui os melanomas subungueal e da mucosa.

O MES é o tipo mais comum de MC que ocorre na população branca com percentual em torno de $70 \%$. Geralmente provem de um nevo pré-existente com predileção para os membros inferiores das mulheres e o dorso dos homens. Em relação ao seu aparecimento ocorre mais precocemente que os tipos MAL e LMM (Chang et al., 1998).

O MN é o segundo em freqüência com percentuais entre 15 a 30\%. O mesmo é semelhante ao MES quanto à localização, porém de aparecimento mais tardio em relação a este. Surge em um nevo pré-existente ou de novo e por definição, desde o início, apresenta crescimento vertical. Característica que deve justificar seu maior potencial para produzir metástases.

O MAL é a principal forma de MC em indivíduos não-brancos, provavelmente pela não ocorrência das outras formas nestes pacientes. Relata-se $0,7 \%$ de MC não acral em pacientes não-brancos (Slingluff Jr et al., 1990). O seu diagnóstico geralmente ocorre em um 
estádio avançado em relação às outras formas. Isto é explicado por vários fatores: pela sua ocorrência em localizações observadas apenas casualmente, por serem freqüentemente ignorados pela errônea concepção que MC ocorre apenas em áreas expostas ao sol e que o MC não ocorre em pacientes não-brancos. Alem disto, muitas vezes são confundidos com processos benignos, portanto subestimados e ocorrem em regiões nem sempre favoráveis a serem submetidas à biopsia. Em pacientes brancos o MAL representa apenas $2 \%$ a $8 \%$ dos tumores e $30 \%$ a $90 \%$ dos MC em pacientes não-brancos (30 a 50\% em asiáticos e 60 a 70\% em negros) (Reintgen et al., 1982; Seiji e Takahashi, 1982).

Quanto ao LMM, 5 a $10 \%$ de todos os tumores, demonstrase que esta forma ocorre em áreas cronicamente expostas ao sol e em indivíduos idosos. A maioria dos pacientes, em torno de 75\%, tem mais de 60 anos e a localização preferencial é a face (Cohen, 1995). A fase de crescimento radial pode durar até mais de 15 anos antes de invadir a derme e a taxa de invasão é menor que $5 \%$, porém quando esta ocorre o prognóstico dependerá da espessura tumoral, como ocorre nas outras formas (Weinstock e Sober, 1987).

Quanto aos tipos de crescimento, na região sul do Brasil, onde as casuísticas tratam de pacientes da cor branca, encontra-se na 
grande maioria predomínio do padrão MES (50 a 60\%) seguidos do MN (20 a 30\%) e do LMM (10 a 20\%). O MAL é o menos incidente com 2 a 10\% dos pacientes (Bakos 1991; Bakos et al., 1998; Bernardi et al., 1998; Bakos et al., 2002; Moreno, 2005) (Quadro 1 ). Para as outras regiões brasileiras, os dados quanto aos padrões de crescimento são escassos. Um único trabalho revela os seguintes números: MES 63\%, MAL 23\%, MN 12,3\% e LMM 1,5\%; com o aumento relativo do MAL (Fernandes et al., 2005) (Quadro 2). 
Quadro 1 - Dados dos autores nacionais da região sul quanto à cor, ao sexo, à idade, à localização da lesão primária e ao tipo de crescimento do melanoma cutâneo em suas casuísticas

\begin{tabular}{|c|r|c|c|r|c|c|}
\hline $\begin{array}{c}\text { Região } \\
\text { Sul }\end{array}$ & $\begin{array}{c}\mathrm{N} \text { de } \\
\text { casos }\end{array}$ & $\begin{array}{c}\text { Cor } \\
(\%)\end{array}$ & $\begin{array}{c}\text { Sexo } \\
(\%)\end{array}$ & Idade (anos) $(\%)$ & $\begin{array}{c}\text { Local } \\
(\%)\end{array}$ & $\begin{array}{c}\mathrm{TC} \\
(\%)\end{array}$ \\
\hline $\begin{array}{c}\text { Minelli } \\
1983\end{array}$ & 59 & $\mathrm{~B}(96,6)$ & $\mathrm{F}(57,6)$ & $40-60(47,6)$ & $\mathrm{E}(42,0)$ & - \\
\hline $\begin{array}{c}\text { Bakos } \\
1991\end{array}$ & 153 & $\mathrm{~B}(100,0)$ & $\mathrm{M}(60,1)$ & $60-70(23,0)$ & - & $\mathrm{MES}(51,6)$ \\
\hline $\begin{array}{c}\text { Venegas } \\
1992\end{array}$ & 101 & $\mathrm{~B}(99,0)$ & $\mathrm{F}(55,0)$ & $36-55(48,7)$ & $\mathrm{E}(36,7)$ & $\mathrm{MN}(36,6)$ \\
\hline $\begin{array}{c}\text { Nasser } \\
1993\end{array}$ & 209 & $\mathrm{~B}(100,0)$ & $\mathrm{F}(50,5)$ & $<65(78,2)$ & - & $\mathrm{MES}(36,5)$ \\
\hline $\begin{array}{c}\text { Bernardi } \\
1998\end{array}$ & 167 & $\mathrm{~B}(100,0)$ & $\mathrm{M}(53,1)$ & - & $\mathrm{E}(41,3)$ & $\mathrm{MES}(50,0)$ \\
\hline $\begin{array}{c}\text { Gon } \\
2001\end{array}$ & 303 & $\mathrm{~B}(100,0)$ & $\mathrm{M}(54,4)$ & - & - & $\mathrm{MN}(41,1)$ \\
\hline $\begin{array}{c}\text { Bakos } \\
2002\end{array}$ & 103 & $\mathrm{~B}(99,0)$ & $\mathrm{M}(66,9)$ & - & $\mathrm{E}(40,8)$ & $\mathrm{MES}(61,2)$ \\
\hline $\begin{array}{c}\text { Moreno } \\
2005\end{array}$ & 129 & $\mathrm{~B}(100,0)$ & $\mathrm{M}(56,7)$ & - & $\mathrm{E}(38,9)$ & $\mathrm{MES}(57,8)$ \\
\hline
\end{tabular}

Nota: B (Branco), NB (Não branco), M (Masculino), F(Feminino), E (Extremidades), TC (Tipo de crescimento) MES (melanoma expansivo superficial), MN (melanoma nodular).

Quadro 2 - Dados dos autores nacionais de outras regiões, quanto à cor, ao sexo, à localização da lesão primária e ao tipo de crescimento do melanoma cutâneo em suas casuísticas

\begin{tabular}{|c|c|c|c|r|r|c|}
\hline $\begin{array}{c}\text { Outras } \\
\text { regiões }\end{array}$ & $\begin{array}{c}\mathrm{N} \text { de } \\
\text { casos }\end{array}$ & $\begin{array}{c}\text { Cor } \\
(\%)\end{array}$ & $\begin{array}{c}\text { Sexo } \\
(\%)\end{array}$ & Idade (anos) (\%) & Local (\%) & $\begin{array}{c}\text { TC } \\
(\%)\end{array}$ \\
\hline $\begin{array}{c}\text { Bandiera } \\
1967\end{array}$ & 275 & $\mathrm{~B}(92,8)$ & $\mathrm{F}(50 \%)$ & $40-60(21,7)$ & $\mathrm{E}(50,6)$ & - \\
\hline $\begin{array}{c}\text { Fernandes } \\
1996\end{array}$ & 47 & $\mathrm{~B}(84,4)$ & $\mathrm{F}(57,4)$ & $40-60(44,6)$ & $\mathrm{E}(50,9)$ & $\mathrm{LMM}(29,8)$ \\
\hline $\begin{array}{c}\text { Giavina- } \\
\text { Bianchi } \\
1996\end{array}$ & 115 & - & $\mathrm{F}(66,1)$ & $61-70(23,4)$ & $\mathrm{E}(66,0)$ & - \\
\hline $\begin{array}{c}\text { Brandão } \\
1998\end{array}$ & 76 & $\mathrm{~B}(82,8)$ & $\mathrm{M}(55,2)$ & - & $\mathrm{T}+\mathrm{E}(86,8)$ & $\mathrm{MES}(42,1)$ \\
\hline $\begin{array}{c}\text { Criado } \\
1999\end{array}$ & 222 & $\mathrm{~B}(98,1)$ & $\mathrm{F}(69,3)$ & $\begin{array}{c}(\mathrm{F}) 50-60(25,3) \\
(\mathrm{M}) 60-69(22,5)\end{array}$ & $\begin{array}{c}(\mathrm{M}) \mathrm{T}(29,4) \\
(\mathrm{F}) \mathrm{E}(38,3)\end{array}$ & - \\
\hline $\begin{array}{c}\text { Lapa } \\
2002\end{array}$ & 115 & $\mathrm{~B}(94,0)$ & $\mathrm{F}(64,0)$ & $40-60(43,5)$ & $\mathrm{CP}, \mathrm{T}(61,0)$ & $\mathrm{MN}(19,1)$ \\
\hline $\begin{array}{c}\text { Pinheiro } \\
2003\end{array}$ & 32 & $\mathrm{~B}(87,5)$ & $\mathrm{F}(78,0)$ & - & $\mathrm{E}(50,0)$ & - \\
\hline $\begin{array}{c}\text { Fernandes } \\
2005\end{array}$ & 65 & $\mathrm{~B}(83,1)$ & $\mathrm{F}(50,8)$ & $60-80(40,0)$ & - & $\mathrm{MES}(63,0)$ \\
\hline
\end{tabular}

Nota: B (Branco), NB (Não branco), M (Masculino), F (Feminino), E (Extremidades), T (Tronco), CP (Cabeça e pescoço), TC (Tipo de crescimento) MES (melanoma expansivo superficial), MN (melanoma nodular), LMM (lentigo maligno melanoma). 


\subsection{Dados histopatológicos}

\subsubsection{Espessura tumoral}

A espessura de Breslow é considerada, atualmente, o principal fator prognóstico para o MC (Balch et al., 2001a). Quanto maior a espessura tumoral maior o risco de desenvolver recorrência local, metástases em trânsito e satélites, além de metástases linfonodais e sistêmicas. Deste modo, a espessura de Breslow determina a medida das margens cirúrgicas e a indicação ou não da pesquisa do linfonodo sentinela (Schultz et al., 1990; Balch et al., 2001a).

A classificação da AJCC de 2002, utilizada para o estadiamento dos pacientes, baseia-se essencialmente na espessura de Breslow para a classificação do tumor primário (Balch et al., 2001a). Em estudo multicêntrico internacional, com grande casuística, verifica-se freqüência de $39,0 \%$ de tumores com espessura de Breslow até $1 \mathrm{~mm}, 29,0 \%$ para o intervalo de 1,01 a 2,0 mm, 21,7\% para o intervalo de 2,01 a $4,0 \mathrm{~mm}$ e $10,1 \%$ para tumores acima de 4,0mm (Balch et al., 2001b).

Quanto à incidência do MC e sua espessura tumoral demonstra-se nos EUA, entre 1986 e 1996, aumento da incidência de 
tumores finos, menores de $1,0 \mathrm{~mm}$, e incidência de tumores mais espessos que 4,0 mm mantida estável (Jemal et al., 2001; Weinstock e Mikkilinemi, 2001). Estes dados também são confirmados para outros países. Na Nova Zelândia demonstra-se diminuição do número dos tumores espessos, maiores que 0,75 mm, em homens e em mulheres abaixo de 65 anos; exceção feita para homens acima de 75 anos, onde se verifica aumento do número de tumores espessos (Marrett et al., 2001). Fato que também é relatado nos EUA (Dennis, 1999; Jemal et al., 2001; Lee, 2001).

A espessura média dos tumores, na Europa, decaiu de 1,2 para $0,8 \mathrm{~mm}$, enquanto na Austrália, em Queensland houve pequeno aumento, passando de 0,5 para $0,6 \mathrm{~mm}$, com a prevalência de tumores mais espessos em homens idosos (Garbe et al., 2000). Na França demonstra-se aumento de MC finos e incidência estável de MC espessos (Lipsker et al., 1999). Na Holanda apresenta-se espessura média diminuída de 1,2 para 1,1 em homens e de 1,1 para $0,8 \mathrm{~mm}$ em mulheres (van der Rhee et al., 1999) (Quadro 3).

Em relação às medidas da espessura de Breslow, na literatura brasileira os dados são escassos e não apresentam uniformidade nas suas descrições. Existem relatos demonstrando apenas 20 a $30 \%$ de casos de MC com espessuras abaixo de 0,75 
mm. (Venegas et al., 1992; Criado et al., 1999; Gon et al., 2001). As médias das espessuras relatadas são 3,09mm e 3,17mm (Gon et al., 2001; Moreno, 2005) e a mediana de 2,06mm (Gon et al., 2001) (Quadro 3 ).

Quadro 3 - Espessura média de Breslow em milímetros de acordo com os seguintes autores, por local de origem e ano de publicação

\begin{tabular}{c|c} 
com os seguintes autores, por local de origem e ano de publicação \\
\hline Autores & Espessura $(\mathrm{mm})$ \\
\hline van der Rhee et al & $1,10(\mathrm{M})$ \\
1999 (Europa) & $0,80(\mathrm{~F})$ \\
Garbe et al & 0,80 \\
2000 ( Europa) & \\
$\quad$ Garbe et al & 0,60 \\
2000 (Austrália) & \\
$\quad$ Gon et al & 2,06 \\
2001 (Brasil) & \\
Moreno et al & 3,09 \\
2005 (Brasil) & \\
\hline
\end{tabular}

Nota: M (Masculino), F (Feminino).

\subsubsection{Presença de ulceração}

Documentada no exame histopatológico, a presença de ulceração representa o segundo fator prognóstico independente mais importante na determinação da sobrevida dos pacientes com MC. Também faz parte da classificação da AJCC de 2002. Pacientes com tumores ulcerados têm sobrevida igual aos pacientes com um estádio subseqüente (Mackie et al., 1995; Marghoob et al., 2000; Balch et al., 2001a; Retsas et al., 2002; Eigentler et al., 2004). 
Existe clara correlação entre a espessura tumoral e a presença de ulceração. Conforme a espessura aumenta a presença de ulceração também. Os MC finos, com espessura menor que $1,0 \mathrm{~mm}$, apresentam $6 \%$ de presença de ulceração enquanto os MC espessos, maiores de 4,0 mm, apresentam 63\%. (Balch et al., 2001b).

$\mathrm{Na}$ literatura brasileira encontra-se citação quanto à presença de ulceração no exame histopatológico em apenas um trabalho, com $43,6 \%$ de ocorrência sem referência as espessuras (Venegas et al., 1992).

\subsubsection{Nível de Clark}

O sistema de microestadiamento de Clark considera o nível de invasão do tumor primário em relação às camadas da pele. O nível I indica células neoplásicas restritas a epiderme (melanoma in situ); o nível II células que ultrapassam a membrana basal dermo-epidérmica acometendo parcialmente a derme papilar; o nível III ocupação completa da derme papilar; o nível IV invasão da derme reticular; o nível V invasão do tecido celular subcutâneo (Clark Jr et al., 1969).

Os níveis de Clark apresentam correlação inversamente proporcional à sobrevida, entretanto esta correlação não é tão precisa quanto a proporcionada pela medida da espessura tumoral (Morton et 
al., em 1993). Seu valor prognóstico é menos significativo para o MC com espessura maior que um milímetro. Atualmente valoriza-se o nível de Clark nos pacientes com MC com espessura menor ou igual a um milímetro (Balch et al., 2001a; Buettner et al., 2005).

Quanto ao nível de Clark, as casuísticas brasileiras em sua maioria apresentam predomínio dos níveis III e IV com percentuais compreendidos entre 70 e $80 \%$ dos casos (Giavina-Bianchi et al., 1996; Donato et al., 1997; Bernardi et al., 1998; Criado et al., 1999; Gon et al., 2001; Lapa et al., 2002; Moreno, 2005). 
CASUÍSTICA E MÉTODOS 


\subsection{Casuística}

Entre Maio de 1993 a Janeiro de 2006, 364 pacientes com MC foram registrados, tratados e seguidos na Unidade de Melanoma da Santa Casa de São Paulo (UMSC-SP), serviço pertencente à Clínica de Dermatologia desta mesma entidade.

Deste total, em janeiro de 2006 sete pacientes se encontravam em processo de estadiamento aguardando exames. Dos restantes 357, 250 pacientes entraram no protocolo com doença localizada (restrita a pele, sem metástases de qualquer forma), 74 apresentavam-se com doença loco-regional (metástase linfonodal regional ao tumor ou em trânsito) e 33 pacientes apresentavam doença sistêmica, com metástases à distância.

Todos os pacientes, na ocasião de sua admissão na UMSC$\mathrm{SP}$, foram incluídos em protocolo informatizado dentro dos programas Access e Epi-info 2002 (Anexo 1). 


\subsection{Métodos}

\subsubsection{Critérios de inclusão}

Todos os casos deveriam ter diagnóstico de MC confirmado por exame anátomo-patológico e com dados clínicos fidedignos. Nos casos em que a análise histopatológica, através da coloração da hematoxilina-eosina, não foi conclusiva foram realizados estudos imunohistoquímicos da proteína S-100 e HMB-45. Todos os exames anátomo-patológicos realizados na UMSC-SP foram laudados por um único examinador.

A partir do diagnóstico, os pacientes foram examinados clinicamente e submetidos aos seguintes exames para estadiamento: hemograma completo, dosagem sérica da desidrogenase láctica $(\mathrm{DHL})$, radiografia de torax póstero-anterior e perfil esquerdo, ultrasonografia abdominal. Quando se fez necessário esclarecer dúvida diagnóstica, cintilografia óssea, tomografias e ressonâncias magnéticas complementares foram realizadas.

Todos os pacientes foram tratados cirurgicamente com a realização de excisão com margens preconizadas conforme a espessura de Breslow e baseada nas recomendações da American Joint Committee on Cancer de 2002 (AJCC) (Anexo 3). 
Até o ano de 2002 empregamos margens cirúrgicas de um centímetro para espessura menor de um milímetro. Acima ou igual a um milímetro executamos margens de até três centímetros.

A partir do ano de 2002 utilizamos margens cirúrgicas de um centímetro para tumores com até um milímetro de espessura. Quando exeqüível empregamos dois centímetros de margem para lesões com mais de um milímetro e obrigatoriamente para os tumores com dois milímetros ou mais de espessura.

Nas lesões extensas foram realizadas biopsias incisionais. Naquelas que se apresentavam elevadas, as biopsias foram realizadas na área mais espessa e naquelas maculosas, na área mais enegrecida.

A amostra foi descrita quanto às características demográficas: sexo, idade, cor, quanto às características clínicopatológicas: localização do tumor primário, tipo de crescimento, espessura de Breslow, nível de Clark, presença de ulceração e quanto ao estadiamento proposto pelo AJCC de 2002 (Anexos 2-3). 


\subsubsection{Critérios de avaliação das variáveis}

Estadiamento: Para esta análise os pacientes foram categorizados nos seguintes grupos: pacientes com doença localizada, onde o MC não apresentava metástases loco-regional nem sistêmica, pacientes com doença loco-regional onde o MC acometia a cadeia linfática próxima ao tumor ou apresentava-se em trânsito e pacientes com doença sistêmica com comprometimento à distância do MC.

Nos casos onde o nível de Clark, a espessura de Breslow e a presença ou não de ulceração foram informados, procedemos ao estadiamento preconizado pela AJCC de 2002 (Anexo 3).

Letalidade: É definida como a relação entre os óbitos e os casos de uma doença, portanto não tem o mesmo significado que mortalidade que é relação entre os óbitos e a população geral ou específica de uma área. Pôde-se, para esta amostra, calcular apenas o coeficiente de letalidade.

Idade: A data da primeira consulta foi utilizada para o cálculo da idade do paciente. Para a estatística descritiva relativa á idade foi utilizada apenas os casos do grupo com doença localizada, por estes apresentarem exatidão quanto ao momento do diagnóstico inicial. Adicionalmente os pacientes foram divididos em dois grupos, 
até 65 anos e acima de 65 anos, pois se optou por considerar idosos pacientes acima de 65 anos. Além disso, os pacientes foram classificados em faixas etárias com intervalos de dez e vinte anos.

Cor: Os pacientes foram divididos em dois grupos, brancos e não-brancos. Este último grupo incluiu os pacientes negros, pardos e amarelos.

Localização da lesão primária: Os pacientes foram divididos em três grupos, pacientes com MC localizados na cabeça e pescoço, no tronco e tumores localizados nas extremidades. Para os tumores localizados nas extremidades estes se subdividiram nas seguintes regiões: pernas, braços, mãos e pés e estes últimos, em dorso de mão, dorso de pé, região plantar, calcâneo e subungueal.

Tipo de crescimento: A classificação foi baseada nos dados clínicos e histopatógicos dos casos. Os tipos de crescimento foram os seguintes: melanoma expansivo superficial (MES), melanoma lentigo maligno (LMM), melanoma nodular ( $M N)$ e melanoma acrolentiginoso (MAL) e outros, onde se incluem o tipo desmoplásico e as formas onde não foi possível a classificação.

Espessura tumoral: Neste trabalho dividimos os tumores conforme a classificação da AJCC de 2002, a saber, $=1,0 \mathrm{~mm}$, de 1,01 a 2,0 mm, 2,01 a 4,0mm e $>4,0 \mathrm{~mm}$ de espessura. 
Presença de ulceração: Foi considerada presente quando relatada no exame anátomo-patológico.

\subsubsection{Análise Estatística}

Foram avaliadas inicialmente as freqüências de todas as variáveis estudadas dos pacientes e utilizou-se o intervalo de confiança de $95 \%$. Posteriormente foram analisadas as associações entre as variáveis utilizando-se o teste do qui-quadrado bicaudal. Para tanto se estabeleceu nível de significância de 0,05 e os dados foram analisados através do programa Epi-info 2002. 
RESULTADOS 


\subsection{Descrição quanto ao estadiamento}

No período de maio de 1993 a janeiro de 2006, 364 casos diagnosticados como melanoma cutâneo foram protocolados na UMSC-SP, distribuídos conforme a tabela 1.

Tabela 1 - Distribuição de 364 casos de melanoma cutâneo conforme a apresentação clínica no momento da entrada do paciente no protocolo-UMSC-SP 1993-2006

\begin{tabular}{l|cr}
\hline \multicolumn{1}{c}{ Estadiamento } & freqüência & $\%$ \\
\hline Doença localizada & 250 & 70,0 \\
Doença loco-regional & 74 & 20,7 \\
Doença sistêmica & 33 & 9,2 \\
Em estadiamento & 7 & 0,1 \\
\hline Total & 364 & 100,0 \\
\hline
\end{tabular}

Foi possível a análise microscópica do tumor em 332 casos e assim dividí-los em in situ e invasivos (Tabela 2 ). 
Tabela 2 - Distribuição de 332 casos de melanoma cutâneo quanto à invasão do tumor primário na UMSC-SP 1993-2006

\begin{tabular}{l|cc}
\hline & Número de casos & $\%$ \\
\hline In situ & 52 & 15,7 \\
Invasivo & 280 & 84,2 \\
\hline Total & 332 & 100,0 \\
\hline
\end{tabular}

Destes 332 casos, em 269 casos foi possível categorizar a lesão primária quanto ao microestadiamento, conforme a AJCC 2002 (Tabela 3).

Tabela 3 - Distribuição de 269 casos de melanoma cutâneo invasivos quanto ao microestadiamento da lesão primária, onde "a" representa os tumores sem ulceração e " $b$ " aqueles com ulceração para qualquer pT e com ulceração ou nível de Clark IV ou V para pT1, na UMSC-SP 1993-2006

\begin{tabular}{l|ccr}
\hline Estadiamento & $a$ & $b$ & Total $(\%)$ \\
\hline pT1 $(<$ ou $=1,0 \mathrm{~mm})$ & 51 & 13 & $64(23,9)$ \\
pT2 $(1,01$ a 2,0mm) & 36 & 11 & $47(17,4)$ \\
pT3 $(2,01$ a 4,0mm) & 20 & 31 & $51(18,9)$ \\
pT4(>4,0mm) & 30 & 77 & $107(39,7)$ \\
\hline Total & 137 & 132 & $269(100,0)$ \\
\hline
\end{tabular}

Destes 269 casos, em 251 foi possível categorizá-los quanto à presença de doença linfonodal, conforme a AJCC 2002 (Tabela 4). 
Tabela 4- Distribuição de 251 casos de melanoma cutâneo categorizados quanto à presença de doença linfonodal na UMSC-SP 1993-2006

\begin{tabular}{l|rrrr}
\hline Estadiamento & \multicolumn{3}{|c}{$N O$} & \multicolumn{2}{c}{$N 1-3$} \\
\hline & $\mathrm{n}$ & $\%$ & $\mathrm{n}$ & $\%$ \\
pT1a & 48 & 24,6 & 3 & 5,3 \\
PT1b & 11 & 5,6 & 2 & 3,5 \\
pT2a & 30 & 15,3 & 5 & 8,8 \\
PT2b & 9 & 4,6 & 2 & 3,5 \\
pT3a & 12 & 6,1 & 5 & 8,8 \\
PT3b & 22 & 11,2 & 9 & 16,0 \\
pT4a & 17 & 8,7 & 7 & 12,5 \\
pT4b & 46 & 23,5 & 23 & 41,0 \\
\hline Total & 195 & 100,0 & 56 & 100,0 \\
\hline
\end{tabular}

Dos 269 casos com microestadiamento da lesão primária, em 223 casos foi possível classificá-los quanto à presença de metástases à distância (Tabela 5).

Tabela 5 - Distribuição de 223 casos de melanoma cutâneo categorizados quanto à presença de doença metastática na UMSC-SP 1993-2006

\begin{tabular}{|c|c|c|c|c|}
\hline Estadiamento & \multicolumn{2}{|c|}{ MO } & \multicolumn{2}{|c|}{ M1 } \\
\hline & $n$ & $\%$ & $n$ & $\%$ \\
\hline pT1a & 49 & 24,1 & 2 & 10,0 \\
\hline pT1b & 13 & 6,4 & 0 & \\
\hline pT2a & 34 & 16,7 & 1 & 5,0 \\
\hline pT2b & 11 & 5,4 & 0 & \\
\hline pT3a & 17 & 8,3 & 3 & 15,0 \\
\hline pT3b & 31 & 15,2 & 0 & \\
\hline pT4a & 10 & 4,9 & 6 & 30,0 \\
\hline pT4b & 38 & 18,7 & 8 & 40,0 \\
\hline Total & 203 & 100,0 & 20 & 100,0 \\
\hline
\end{tabular}


Baseado no microestadiamento da lesão primária e no dado relativo à doença loco-regional e ou sistêmica na admissão dos pacientes foi possível proceder ao estadiamento clínico de 354 casos (Tabela 6).

Tabela 6- Distribuição de 354 casos de melanoma cutâneo quanto ao estadiamento clínico na UMSC-SP 1993-2006

\begin{tabular}{l|cc}
\hline Estadiamento & Número de casos & $\%$ \\
\hline EC 0 & 52 & 14,6 \\
EC I & 89 & 25,1 \\
EC II & 106 & 29,9 \\
EC III & 74 & 20,9 \\
EC IV & 33 & 9,3 \\
\hline Total & 354 & 100,0 \\
\hline
\end{tabular}

Nota: EC = Estádio clínico

\subsection{Descrição das variáveis demográficas e clínicas}

\subsubsection{Distribuição quanto ao sexo}

A amostra dividiu-se em 214 pacientes do sexo feminino e 150 do sexo masculino, resultando em uma proporção de 1,4 mulheres para cada homem (Tabela 7).

Tabela 7 - Distribuição de 364 casos de melanoma cutâneo quanto ao sexo na UMSC-SP 1993-2006

\begin{tabular}{c|cc}
\hline Sexo & freqüência & $\%$ \\
\hline Feminino & 214 & 58,8 \\
Masculino & 150 & 41,2 \\
\hline Total & 364 & 100,0 \\
\hline
\end{tabular}




\subsubsection{Distribuição quanto à idade}

A média das idades dos pacientes foi de 58,9 anos e a mediana de 61,0 anos. Divididos por faixas etárias encontrou-se números absolutos e percentuais conforme a tabela 8 .

Tabela 8- Distribuição de 250 casos de melanoma cutâneo com doença localizada, quanto à idade, em intervalos de 20 anos na UMSC-SP 1993-2006

\begin{tabular}{c|cc}
\hline Idade & Numero de casos & $\%$ \\
$=20$ & 1 & 0,4 \\
$21-40$ & 35 & 14,0 \\
$41-60$ & 84 & 33,6 \\
$61-80$ & 114 & 45,6 \\
$>80$ & 16 & 6,4 \\
\hline Total & 250 & 100,0 \\
\hline
\end{tabular}

Nota: Para o cálculo da variável idade foram considerados apenas os pacientes com doença localizada, onde a idade do paciente condizia com o diagnóstico.

\subsubsection{Distribuição quanto à cor}

A amostra constitui-se de $314(86,3 \%)$ pacientes brancos, $34(9,3 \%)$ negros, $14(3,8 \%)$ pardos e $2(0,5 \%)$ asiáticos (Tabela 9).

Tabela 9- Distribuição de 364 casos de melanoma cutâneo quanto à cor dos pacientes na UMSC-SP 1993-2006

\begin{tabular}{c|cc}
\hline Cor & freqüência & $\%$ \\
\hline Brancos & 314 & 86,3 \\
Não-brancos & 50 & 13,7 \\
\hline Total & 364 & 100,0 \\
\hline
\end{tabular}




\subsubsection{Distribuição quanto à localização da lesão}

\section{primária}

As lesões estiveram localizadas, 178 nos membros, 105 no tronco e 69 na cabeça e pescoço, 12 apresentaram-se sem lesão primária (Tabela 10).

Tabela 10- Distribuição de 364 casos de melanoma cutâneo quanto à localização da lesão primária na UMSC-SP 1993-2006

\begin{tabular}{l|cc}
\hline \multicolumn{1}{c}{ Localização } & freqüência & $\%$ \\
\hline Extremidades & 178 & 50,6 \\
Tronco & 105 & 29,8 \\
Cabeça e pescoço & 69 & 19,6 \\
Sem lesão primária & 12 & 3,2 \\
\hline Total & 364 & 100,0 \\
\hline
\end{tabular}

\subsubsection{Distribuição quanto ao tipo de crescimento}

Os pacientes foram classificados conforme os subtipos histológicos como consta na tabela 11 . Vinte e três casos $(6,3 \%)$ representavam outros padrões de crescimento e pacientes onde as classificações não foram possíveis. 
Tabela 11- Distribuição de 364 casos de melanoma cutâneo quanto ao tipo de crescimento na UMSC-SP 1993-2006

\begin{tabular}{c|cc}
\hline Tipo de crescimento & freqüência & $\%$ \\
\hline MES & 123 & 33,8 \\
MN & 95 & 26,1 \\
MAL & 81 & 22,3 \\
LMM & 42 & 11,5 \\
Outros & 23 & 6,3 \\
\hline Total & 364 & 100,0 \\
\hline
\end{tabular}

Nota: MES, melanoma expansivo superficial, MN, melanoma nodular, MAL, melanoma acrolentiginoso, LNM, lentigo maligno melanoma, Outros $=$ outros padrões de crescimento ou não classificados.

\subsection{Descrição quanto as variáveis histológicas}

\subsubsection{Distribuição quanto à espessura tumoral}

A espessura média dos tumores primários foi de $4,88 \mathrm{~mm}$ e a mediana 2,5 mm. Em 20 casos (5,6\%) não foi possível obter tal dado. A distribuição dos casos, nos intervalos de espessura de Breslow, preconizados pela AJCC 2002 está demonstrado na tabela 12.

Tabela 12 - Distribuição de 332 casos de melanoma cutâneo quanto à espessura de Breslow na UMSC-SP 1993-2006

\begin{tabular}{c|cc}
\hline Espessura de Breslow & freqüência & $\%$ \\
\hline In situ & 52 & 15,7 \\
$=1,0 \mathrm{~mm}$ & 67 & 23,9 \\
1,01 a $2,0 \mathrm{~mm}$ & 48 & 14,5 \\
2,01 a $4,0 \mathrm{~mm}$ & 52 & 15,7 \\
$>4,0 \mathrm{~mm}$ & 113 & 34,0 \\
\hline Total & 332 & 100,0 \\
\hline
\end{tabular}




\subsubsection{Distribuição quanto aos níveis de Clark}

Em 18 casos $(5,1 \%)$ não se conhecia o dado. A distribuição quanto aos níveis apresenta-se na tabela 13.

Tabela 13 - Distribuição de 332 casos de melanoma cutâneo quanto aos níveis de Clark na UMSC-SP 1993-2006

\begin{tabular}{c|cc}
\hline Níveis de Clark & freqüência & $\%$ \\
\hline I & 52 & 15,6 \\
II & 49 & 14,7 \\
III & 78 & 23,4 \\
IV & 85 & 25,4 \\
V & 68 & 20,4 \\
\hline Total & 332 & 100,0 \\
\hline
\end{tabular}

\subsubsection{Distribuição quanto à presença de ulceração}

Em apenas 27 casos $(7,6 \%)$ não foi informado o dado. A distribuição dos casos pode ser observada na tabela 14.

Tabela 14 - Distribuição de 270 casos de melanoma cutâneo invasivo quanto à presença de ulceração na UMSC-SP 1993-2006

\begin{tabular}{c|cc}
\hline Presença de ulceração & freqüência & $\%$ \\
\hline Sim & 128 & 47,4 \\
Não & 142 & 52,6 \\
\hline Total & 270 & 100,0 \\
\hline
\end{tabular}




\subsection{Correlação entre as variáveis}

\subsubsection{Sexo e idade}

A distribuição de 250 casos de melanoma cutâneo para as faixas etárias com intervalos de 10 anos em relação ao sexo apresentou, com exceção da faixa etária entre 81-90 anos, nítido predomínio de mulheres em relação aos homens (gráfico 1).

Gráfico 1- Distribuição de 250 casos de melanoma cutâneo conforme a idade e o sexo dos pacientes, em intervalos de dez anos, na UMSCSP 1993-2006

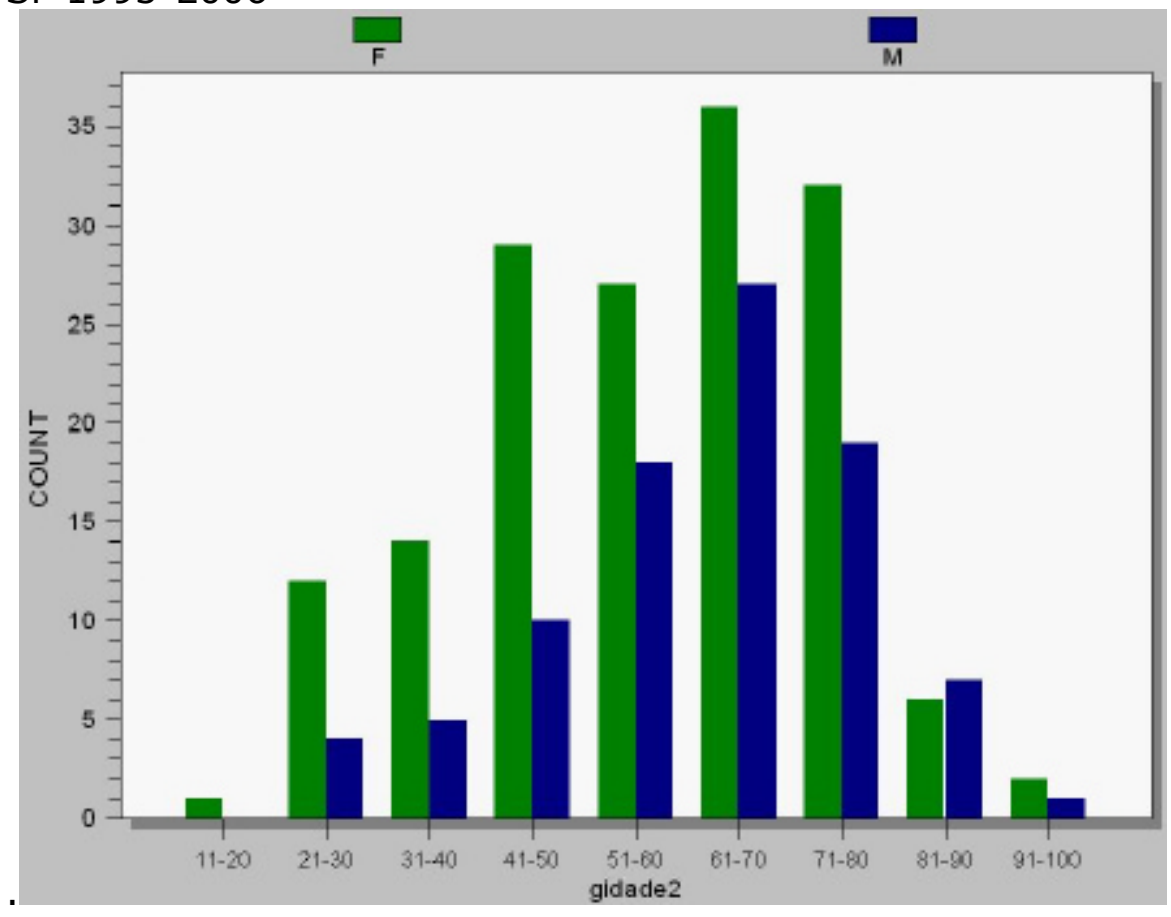




\subsubsection{Sexo e localização da lesão primária}

Quanto ao sexo e as diferentes localizações da lesão primária do MC, mulheres apresentaram predomínio de tumores localizados nos membros e homens nos membros e tronco (Tabela 15).

Tabela 15 - Distribuição de 352 casos de melanoma cutâneo quanto ao sexo em relação à localização da lesão primária na UMSC-SP 19932006

\begin{tabular}{l|cccc}
\hline \multicolumn{1}{c|}{ Localização } & \multicolumn{2}{c}{ Feminino } & \multicolumn{2}{c}{ Masculino } \\
\hline & freqüência & $\%$ & freqüência & $\%$ \\
Cabeça e pescoço & 42 & 20,0 & 27 & 19,0 \\
Tronco & 51 & 24,3 & 54 & 38,0 \\
Braços & 23 & 10,9 & 12 & 8,4 \\
Pernas & 35 & 16,6 & 13 & 9,1 \\
Mãos & 12 & 5,7 & 2 & 1,4 \\
Pés & 45 & 21,4 & 34 & 23,9 \\
\hline Total & 210 & 100,0 & 142 & 100,0 \\
\hline
\end{tabular}

\subsubsection{Sexo e tipo de crescimento}

A análise dos sexos em relação aos tipos de crescimento está representada na tabela 16. 
Tabela 16- Distribuição de 364 casos de melanoma cutâneo quanto ao sexo em relação aos tipos de crescimento na UMSC-SP 1993-2006

\begin{tabular}{l|cccc}
\hline Tipo de crescimento & \multicolumn{2}{|c}{ Feminino } & \multicolumn{2}{c}{ Masculino } \\
\hline & Freqüência & $\%$ & Freqüência & $\%$ \\
LMM & 28 & 13,1 & 14 & 9,3 \\
MES & 80 & 37,4 & 43 & 28,7 \\
MN & 47 & 22,0 & 48 & 32,0 \\
MAL & 49 & 22,9 & 32 & 21,3 \\
Outros & 10 & 4,7 & 13 & 8,7 \\
\hline Total & 214 & 100,0 & 150 & 100,0 \\
\hline
\end{tabular}

$\mathrm{P}=0,066$

Nota LMM, lentigo maligno melanoma, MES, melanoma expansivo superficial, MN, melanoma nodular, MAL melanoma acrolentiginoso, Outros, outros padrões de crescimento ou não classificados.

\subsubsection{Sexo e espessura tumoral}

A distribuição dos sexos para os intervalos de espessura de

Breslow encontra-se na tabela 17.

Tabela 17 - Distribuição de 274 casos de melanoma cutâneo quanto ao sexo em relação à espessura de Breslow na UMSC-SP 1993-2006

\begin{tabular}{c|cccc}
\hline Espessura de Breslow & \multicolumn{2}{|c}{ Feminino } & \multicolumn{2}{c}{ Masculino } \\
\hline & freqüência & $\%$ & freqüência & $\%$ \\
$1,0 \mathrm{~mm}$ & 49 & 42,1 & 15 & 26,2 \\
1,01 a $2,0 \mathrm{~mm}$ & 30 & 18,0 & 17 & 15,7 \\
2,01 a $4,0 \mathrm{~mm}$ & 26 & 27,7 & 27 & 33,8 \\
> 4,0 mm & 61 & 30,2 & 49 & 40,0 \\
\hline Total & 166 & 100,0 & 108 & 100,0 \\
\hline
\end{tabular}

$p=0,011$

\subsubsection{Sexo e presença de ulceração}

A correlação do sexo dos pacientes com a presença de ulceração na lesão primária pode ser observada na tabela 18 . Os 
homens apresentaram $52 \%$ de lesões ulceradas, e as mulheres 33,3\%, demonstrando-se diferença significativa (Tabela 18).

Tabela 18 - Distribuição de 325 casos de melanoma cutâneo quanto ao sexo em relação à presença de ulceração na UMSC-SP 1993-2006

\begin{tabular}{c|cccc}
\hline $\begin{array}{c}\text { Presença de } \\
\text { ulceração }\end{array}$ & \multicolumn{3}{|c}{ Feminino } & \multicolumn{2}{c}{ Masculino } \\
\hline & freqüência & $\%$ & freqüência & $\%$ \\
Sim & 66 & 33,3 & 66 & 52,0 \\
Não & 132 & 66,7 & 61 & 48,0 \\
\hline Total & 198 & 100,0 & 127 & 100,0 \\
\hline
\end{tabular}

$\mathrm{p}<0,001$

\subsubsection{Idade e localização da lesão primária}

Cerca de cinqüenta por cento das lesões ocorreram nas extremidades e foram distribuídas igualmente para os dois grupos etários previamente determinados, abaixo e acima de 65 anos. No restante houve predomínio de lesões localizados no tronco em não idosos e tumores na cabeça e pescoço em pacientes idosos (Tabela 19). 
Tabela 19- Distribuição de 249 casos com melanoma cutâneo quanto à idade em relação à localização da lesão primária na UMSCSP $1993-2006$

\begin{tabular}{l|cccc}
\hline \multicolumn{1}{c|}{ Localização } & \multicolumn{2}{c}{$=65$ anos } & \multicolumn{2}{c}{$>65$ anos } \\
\hline & freqüência & $\%$ & freqüência & $\%$ \\
Cabeça e pescoço & 22 & 14,8 & 35 & 33,3 \\
Tronco & 51 & 34,4 & 18 & 17,1 \\
Braços & 22 & 14,8 & 9 & 8,9 \\
Pernas & 25 & 16,8 & 5 & 4,9 \\
Mãos & 4 & 2,7 & 6 & 5,9 \\
Pés & 24 & 16,2 & 28 & 27,7 \\
\hline Total & 148 & 100,0 & 101 & 100,0 \\
\hline
\end{tabular}

\subsubsection{Idade e tipo de crescimento}

$\mathrm{Na}$ análise dos grupos etários em relação aos tipos de crescimento observamos predomínio dos tipos LMM e MAL nos pacientes idosos e dos padrões MES e MN nos pacientes não idosos (Tabela 20).

Tabela 20- Distribuição de 250 casos com melanoma cutâneo quanto à idade em relação ao tipo de crescimento na UMSC-SP 19932006

\begin{tabular}{c|cccc}
\hline Tipo de crescimento & \multicolumn{2}{|c}{$=65$ anos } & \multicolumn{2}{c}{$>65$ anos } \\
\hline & freqüência & $\%$ & freqüência & $\%$ \\
MES & 76 & 52,4 & 23 & 21,9 \\
MN & 34 & 23,4 & 19 & 18,1 \\
MAL & 22 & 15,2 & 33 & 31,4 \\
LMM & 13 & 9,0 & 28 & 26,7 \\
Outros & - & - & 2 & 1,9 \\
\hline Total & 145 & 100,0 & 105 & 100,0 \\
\hline
\end{tabular}

$\mathrm{p}<0,001$

Nota: MES, melanoma expansivo superficial, MN, melanoma nodular, MAL, melanoma acrolentiginoso, LMM, lentigo maligno melanoma,

Outros, outros padrões de crescimento ou não classificado. 


\subsubsection{Idade e espessura tumoral}

A comparação dos grupos etários para os intervalos de espessura de Breslow está apresentada na tabela abaixo (Tabela 21).

Tabela 21- Distribuição de 194 pacientes com melanoma cutâneo quanto à idade e a espessura de Breslow na UMSC-SP 1993-2006

\begin{tabular}{c|cccc}
\hline Espessura de Breslow & \multicolumn{2}{|c}{$=65$ anos } & \multicolumn{2}{c}{$>65$ anos } \\
\hline & freqüência & $\%$ & freqüência & $\%$ \\
$=1,0 \mathrm{~mm}$ & 40 & 33,8 & 17 & 22,3 \\
1,01 a $2,0 \mathrm{~mm}$ & 28 & 23,7 & 10 & 13,1 \\
2,01 a $4,0 \mathrm{~mm}$ & 20 & 16,9 & 16 & 21,0 \\
$>4,0 \mathrm{~mm}$ & 30 & 25,4 & 33 & 43,4 \\
\hline Total & 118 & 100,0 & 76 & 100,0 \\
\hline
\end{tabular}

$p=0,021$

\subsubsection{Idade e presença de ulceração}

$\mathrm{Na}$ análise dos grupos etários em relação à presença de ulceração houve predomínio de casos com ulceração em pacientes com mais de 65 anos (Tabela 22).

Tabela 22- Distribuição de 250 casos com melanoma cutâneo quanto à idade em relação à presença de ulceração na UMSC-SP 1993-2006

\begin{tabular}{c|cccc}
\hline $\begin{array}{c}\text { Presença de } \\
\text { ulceração }\end{array}$ & \multicolumn{3}{|c}{$=65$ anos } & \multicolumn{2}{c}{$>65$ anos } \\
& freqüência & $\%$ & freqüência & $\%$ \\
Sim & 41 & 29,1 & 45 & 43,3 \\
Não & 100 & 70,9 & 59 & 56,7 \\
\hline Total & 141 & 100,0 & 104 & 100,0 \\
\hline
\end{tabular}

$p=0,015$ 


\subsubsection{Cor e localização da lesão primária}

Nos pacientes não-brancos os tumores predominaram nos membros (Tabela 23).

Tabela 23 - Distribuição de 353 casos com melanoma cutâneo quanto à cor dos pacientes em relação à localização da lesão primária na UMSC-SP 1993-2006

\begin{tabular}{l|cccc}
\hline \multicolumn{1}{c|}{ Localização } & \multicolumn{2}{c}{ Brancos } & \multicolumn{2}{c}{ Não-brancos } \\
\hline & freqüência & $\%$ & freqüência & $\%$ \\
Cabeça e pescoço & 65 & 21,0 & 4 & 9,7 \\
Tronco & 100 & 32,3 & 5 & 12,1 \\
Braços & 35 & 11,3 & - & - \\
Pernas & 44 & 14,2 & 4 & 9,7 \\
Mãos & 14 & 4,5 & - & - \\
Pés & 51 & 16,5 & 28 & 68,2 \\
\hline Total & 309 & 100,0 & 41 & 100,0 \\
\hline
\end{tabular}

\subsubsection{Cor e tipo de crescimento}

Houve predomínio das formas LMM, MES e MN nos pacientes brancos e da forma MAL nos pacientes não-brancos como pode se observar na tabela abaixo (Tabela 24). 
Tabela 24 - Distribuição de 364 casos de melanoma cutâneo quanto à cor dos pacientes em relação ao tipo de crescimento na UMSC-SP 1993-2006

\begin{tabular}{c|cccc}
\hline Tipo de crescimento & \multicolumn{2}{|c}{ Brancos } & \multicolumn{2}{c}{ Não-brancos } \\
\hline & freqüência & $\%$ & freqüência & $\%$ \\
MES & 118 & 37,6 & 5 & 10,0 \\
MN & 87 & 27,7 & 8 & 16,0 \\
MAL & 49 & 15,6 & 32 & 64,0 \\
LMM & 40 & 12,7 & 2 & 4,0 \\
Outros & 20 & 6,4 & 3 & 6,0 \\
\hline Total & 314 & 100,0 & 50 & 100,0 \\
\hline
\end{tabular}

$\mathrm{p}<0,001$

Nota: MES, melanoma expansivo superficial, MN, melanoma nodular, $M A L$, melanoma acrolentiginoso, LMM, lentigo maligno melanoma, Outros, outros padrões de crescimento ou não classificado.

A distribuição dos MAL nos pacientes brancos e não-brancos por localização da lesão primária esta demonstrada na tabela 25. Observou-se predomínio de lesões localizadas na região plantar para brancos e não-brancos.

Tabela 25 - Distribuição de 82 casos de melanoma acrolentiginoso quanto à localização da lesão primária nos pacientes brancos e nãobrancos na UMSC-SP 1993-2006

\begin{tabular}{l|rrrr}
\hline Localização & \multicolumn{2}{c}{ Brancos } & \multicolumn{2}{c}{ Não-brancos } \\
\hline & $\mathrm{n}$ & $\%$ & $\mathrm{n}$ & $\%$ \\
Dorso da mão & 1 & 2,0 & - & - \\
Subungueal/mão & 5 & 10,2 & 4 & 12,1 \\
Calcâneo & 5 & 10,2 & 4 & 12,1 \\
Dorso do pé & 5 & 10,2 & - & - \\
Subungueal/pé & 6 & 12,2 & 1 & 3,1 \\
Região plantar & 27 & 55,2 & 24 & 72,7 \\
\hline Total & 49 & 100,0 & 33 & 100,0 \\
\hline
\end{tabular}




\subsubsection{Espessura tumoral e tipo de crescimento}

Os padrões LMM e MES apresentaram espessuras menores e os padrões MN e MAL espessuras maiores (Tabela 26).

Tabela 26- Distribuição de 265 casos de melanoma cutâneo quanto à espessura de Breslow em relação ao tipo de crescimento na UMSCSP 1993-2006

\begin{tabular}{|c|c|c|c|c|c|c|c|c|}
\hline \multirow{2}{*}{$\begin{array}{l}\text { Espessura } \\
\text { de Breslow }\end{array}$} & \multicolumn{2}{|c|}{$L M M$} & \multicolumn{2}{|c|}{ MES } & \multicolumn{2}{|c|}{$M N$} & \multicolumn{2}{|c|}{$\overline{M A L}$} \\
\hline & freq & $\%$ & freq & $\%$ & freq & $\%$ & freq & $\%$ \\
\hline$=1,0 \mathrm{~mm}$ & 7 & 43,7 & 40 & 44,4 & 8 & 8,8 & 7 & 10,1 \\
\hline 1,01 a 2,0 & 5 & 31,2 & 23 & 25,5 & 5 & 5,5 & 13 & 18,8 \\
\hline 2,01 a 4,0 & 1 & 6,2 & 14 & 15,5 & 22 & 24,4 & 15 & 21,7 \\
\hline$>4,0 \mathrm{~mm}$ & 3 & 18,7 & 13 & 14,4 & 55 & 61,1 & 34 & 49,2 \\
\hline Total & 16 & 100,0 & 90 & 100,0 & 90 & 100,0 & 69 & 100,0 \\
\hline
\end{tabular}




\subsection{Evolução dos pacientes}

No grupo com 250 pacientes, que inicialmente se apresentaram com doença localizada, 53 (21,2\%) evoluíram para estádios avançados, sendo $38(15,2 \%)$ para doença loco-regional e 15 (6\%) diretamente para doença sistêmica. Posteriormente, 19 (50\%) dos 38 pacientes que desenvolveram doença loco-regional, também evoluíram para doença sistêmica totalizando 34 (13,6\%) pacientes, oriundos do grupo doença localizada.

No grupo com 74 pacientes com doença loco-regional, 30 casos $(40,5 \%)$ evoluíram para doença sistêmica, os quais, somados aos 19 casos do grupo doença localizada, totalizaram $49(43,7 \%)$ casos.

Ao grupo com doença sistêmica, inicialmente com 33 casos, somaram-se os 15 casos oriundos do grupo doença localizada e 49 casos do grupo doença loco-regional, totalizando 97 casos (Organograma 1). 
Organograma 1- Evolução dos pacientes com MC conforme seu estadiamento inicial, na UMSC-SP 1993-2006
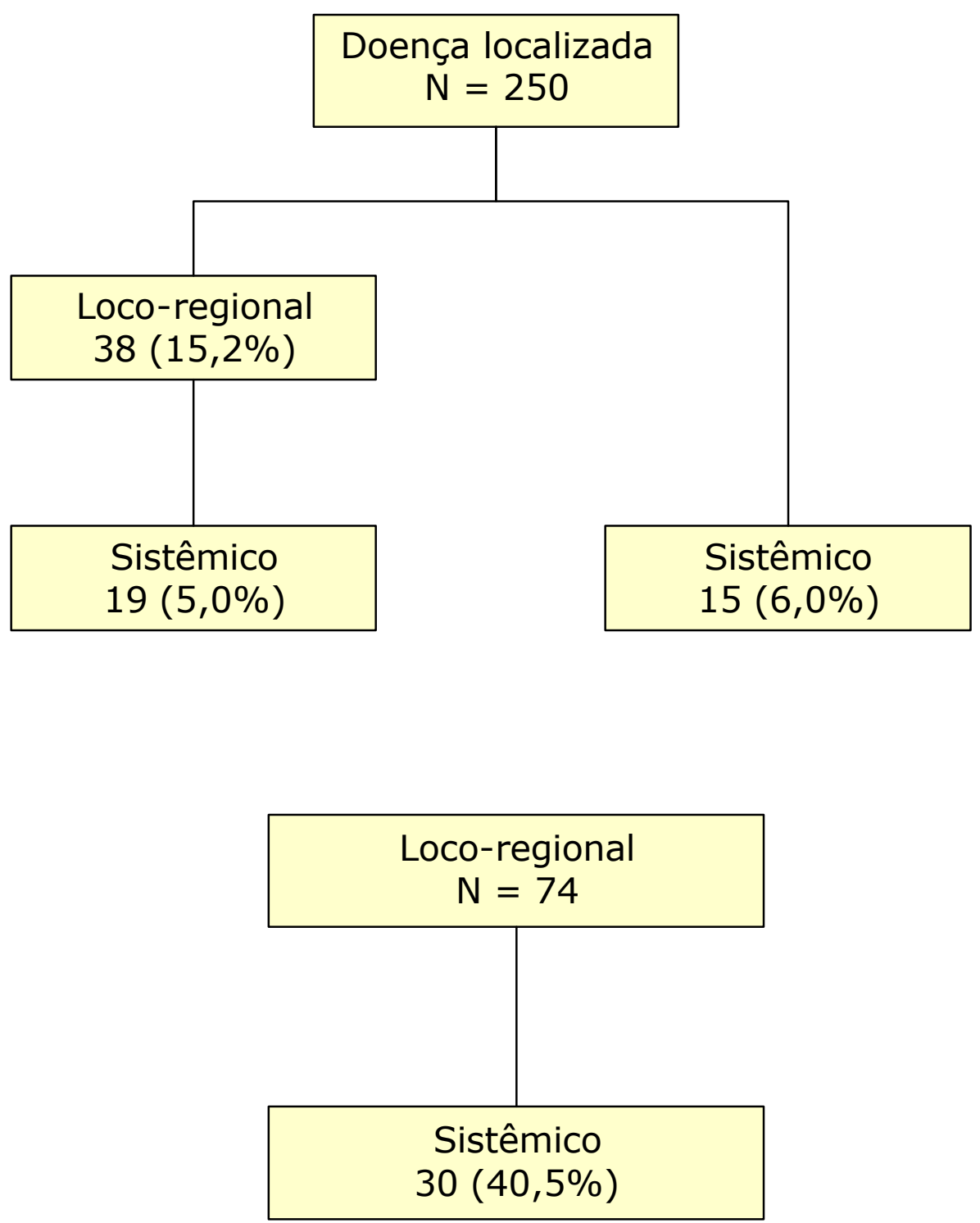


\title{
4.6. Sobrevida média e taxa de sobrevida
}

\begin{abstract}
A sobrevida média para os pacientes com doença localizada foi de 97,8 meses (IC $=91,1$ a 104,5) e a taxa de sobrevida específica para MC foi de $85,1 \%$ em três anos.

A taxa de sobrevida global considerando todos as causas de óbito foi de $81 \%$ em três anos, com a sobrevida média de 88,3 meses (IC $=80,9$ a 95,7). O tempo de seguimento mínimo foi de 1,1 mês e o máximo 117,1 meses. A perda de seguimento foi de $19,7 \%$.
\end{abstract}

\subsection{Letalidade}

A letalidade por MC para esta amostra foi de $24,7 \%$. No grupo com doença localizada ocorreram 46 óbitos em 250 casos: 32 $(12,8 \%)$ por MC e $14(5,6 \%)$ por outras doenças. No grupo com doença loco-regional faleceram 36 pacientes em 74 casos: 35 $(47,3 \%)$ por MC e $1(1,4 \%)$ por outras doenças. No grupo com doença sistêmica morreram 23 pacientes $(69,7 \%)$, todos por MC (Tabela 27). 
Tabela 27 - Distribuição de 357 casos de óbito em relação ao estadiamento inicial dos pacientes com melanoma cutâneo na UMSCSP $1993-2006$

\begin{tabular}{l|rrrrcc}
\hline & \multicolumn{2}{|c}{ Localizada } & \multicolumn{2}{c}{ Loco-regional } & \multicolumn{2}{c}{ Sistêmica } \\
\hline & freq & $\%$ & freq & $\%$ & freq & $\%$ \\
Melanoma & 32 & 12,8 & 35 & 47,3 & 23 & 69,7 \\
Outras causas & 14 & 5,6 & 1 & 1,4 & - & - \\
Total de óbitos & 46 & 18,4 & 36 & 48,7 & 23 & 69,7 \\
Total de casos & 250 & 100,0 & 74 & 100,0 & 33 & 100,0 \\
\hline
\end{tabular}

Nota: freq=freqüência

Agrupando-se os casos pelas suas espessuras observou-se coeficiente de letalidade de $6,2 \%$ para $M C$ finos (= $1 \mathrm{~mm}$, não ulcerados e ulcerados ou Clark IV ou V), 25,5\% para MC de espessura intermediária (1,01 a 4,0 mm, não ulcerados e ulcerados) e 43,9\% para MC espessos (> 4,0 mm não ulcerados e ulcerados) Estes coeficientes de letalidade podem estar subestimados considerando-se que houve perda de seguimento de $19,7 \%$ de pacientes desta casuística (Tabela 28).

Tabela 28 - Índices percentuais relativos ao número de óbitos nos intervalos das espessuras de Breslow de 269 casos de melanoma cutâneo na UMSC-SP 1993-2006

\begin{tabular}{|l|c|c|c|}
\hline $\begin{array}{l}\text { Espessuras de } \\
\text { Breslow }\end{array}$ & $\mathrm{N}^{\circ}$ de casos & $\mathrm{N}^{\circ}$ de óbitos & $\%$ \\
\hline$=1,0 \mathrm{~mm}$ & 64 & 4 & 6,2 \\
\hline $1,01 \mathrm{a} 4,0 \mathrm{~mm}$ & 98 & 25 & 25,5 \\
\hline$>4,0 \mathrm{~mm}$ & 107 & 47 & 43,9 \\
\hline Total de casos & 269 & 76 & - \\
\hline
\end{tabular}


DISCUSSÃO 
O MC é neoplasia maligna, potencialmente fatal, cuja incidência tem aumentando nas últimas décadas. Sua chance de cura está condicionada ao diagnóstico precoce. O conhecimento da epidemiologia desta doença fornece subsídios para aplicação de medidas preventivas primárias e secundárias, fundamentais para determinar estratégias de saúde pública. Estudos com casuísticas significativas e dados fidedignos são imprescindíveis. No Brasil ainda não se dispõe de ampla base de dados que possibilite estudos relacionados à incidência, à taxa de mortalidade e às diversas variáveis demográficas importantes para o conhecimento exato do comportamento da doença.

As casuísticas institucionais isoladas, embora nem sempre forneçam dados que possam ser interpretados como reflexo do desempenho da doença no país, certamente constituem ferramentas para estudos epidemiológicos, clínicos e aplicados. Nas últimas décadas as instituições de referência para o atendimento do MC 
preocupam-se em formar banco de dados com o máximo de informações relevantes.

Em 1993 criou-se a Unidade de Melanoma da Santa Casa do Serviço de Dermatologia do Departamento de Medicina da Faculdade de Ciências Médicas da Santa Casa de São Paulo com o intuito de prover assistência médica de qualidade aos portadores da doença e coleta de dados promissores para o ensino, nos diferentes níveis de graduação e pós-graduação, e para pesquisa. Até janeiro de 2006, 364 casos estavam protocolados na UMSC-SP.

Como em todos os processos implantados, existiram falhas que vêm sendo corrigidas ao longo dos anos. Algumas variáveis puderam ser estudadas para a totalidade dos casos, outras não. Os dados coletados para este estudo possibilitaram a classificação do tumor primário, conforme preconizada pela AJCC de 2002. Para o estadiamento, em relação ao comprometimento linfonodal e sistêmico não houve preocupação em cumprir todos os pressupostos da mesma. Apenas 38 casos foram submetidos à pesquisa do linfonodo sentinela.

Observou-se uma minoria de casos in situ $(14,6 \%$, EC 0$)$ e alto percentual de casos avançados (30,2\%, EC III e EC IV). Cerca de 40,0\% dos tumores primários apresentaram-se espessos ( $>4,0 \mathrm{~mm}$ ) e apenas um quarto da amostra apresentaram-se finos (=1mm). Dos 
MC finos, 25\% apresentaram ulceração ou nível de Clark IV ou V, denotando um percentual de casos com um prognóstico desfavorável. Estudo conduzido para a validação do estadiamento do MC da AJCC, com a análise de 17.600 pacientes provenientes dos EUA, Europa e Austrália, evidencia apenas $10,0 \%$ de $M C$ espessos (> 4,0mm) e 40\% de $M C$ finos (= $1 \mathrm{~mm}$ ), situação inversa à deste estudo (Balch et al., 2001b). Além disso, dados provenientes de países desenvolvidos demonstram aumento da incidência de MC finos e estabilização da incidência de MC espessos (Jemal et al., 2001; Weinstock e Mikkilinemi, 2001).

Praticamente metade dos MC invasivos de indivíduos com doença localizada, loco-regional e sistêmica, da casuística deste presente estudo, apresentaram-se com ulceração. Dentre os MC = $1 \mathrm{~mm}$ o percentual de ulceração foi de 13,4\%. Na literatura internacional encontra-se cerca de $35 \%$ de MC ulcerados para pacientes com doença localizada e $6 \%$ de ulceração para MC finos (Balch et al., 2001b). No Brasil há relato de 43,6\% de MC ulcerados sem distinção para finos ou espessos (Venegas et al., 1992).

Sessenta por cento da casuística deste estudo compôs-se de mulheres, resultando em proporção de 1,4: 1. Este predomínio foi observado em praticamente todas as faixas etárias. A literatura 
internacional faz referência ao predomínio de mulheres em regiões geográficas com baixa insolação e baixos índices de incidência para o MC (Weinstock e Mikkilinemi, 2001). Em países com alta incidência de MC, como a Austrália, verifica-se discreto predomínio do sexo masculino, ou equilíbrio entre os sexos. Embora este presente trabalho refira-se à freqüência de casos e os trabalhos internacionais relatem incidência ajustada para sexo, população e ano, prejudicando a comparação, outros trabalhos brasileiros também demonstram resultados semelhantes a este (Bakos, 1991; Lucas et al., 1994; Fernandes et al., 1996; Giavina-Bianchi et al., 1996; Bernardi et al., 1998; Criado et al., 1999; Bakos et al., 2002; Gon et al., 2001; Lapa et al., 2002; Pinheiro et al., 2003; Moreno, 2005). Curiosamente os trabalhos em língua inglesa apontam, para um futuro próximo, aumento das taxas de MC em homens e declínio em mulheres (Marett et al., 2001; Jemal et al., 2001). No Brasil, dados do Instituto Brasileiro de Geografia e Estatística para o ano de 2000 demonstram proporção semelhante entre homens $(49,2 \%)$ e mulheres $(50,8 \%)$ na população. Entretanto, verifica-se na Clínica Dermatológica da Santa Casa de São Paulo procura maior de mulheres $(56,8 \%)$ por atendimento médico, portanto, possível explicação para o fato de nossa amostra apresentar predomínio de mulheres poderia decorrer 
da maior procura destas por atendimento dermatológico. Outra possível explicação seria a maior exposição solar da mulher durante a vida. Ainda, por ser o Brasil um país tropical, com temperaturas elevadas durante grande período do ano, as mulheres utilizar-se-iam de roupas que permitem exposição maior da pele.

O maior número de casos deste estudo, praticamente $80 \%$, ocorreu na faixa etária compreendida entre 41 a 80 anos, com média e mediana das idades em torno de 60 anos. As médias relatadas pela literatura encontram-se entre 50 e 58 anos (Weinstock e Berwick, 2003) e os trabalhos mostram aumento da incidência em pacientes idosos, o que conseqüentemente aumentará a média em alguns anos (SEER, 2002; AIHW e AACR, 2000). Este fato poderia ser explicado pela menor exposição solar na infância nas últimas décadas, pela maior conscientização das populações, diminuindo assim a incidência do MC em faixas etárias jovens. No Brasil encontramos variabilidade grande entre os autores quanto à faixa etária e a média de idade de aparecimento do MC, com valores tanto abaixo, quanto acima das taxas mundiais, sendo difícil estabelecer um padrão único. Nem todos os autores brasileiros relatam o estadiamento dos pacientes no momento da coleta da idade. O ideal seria a utilização de dados 
referentes a pacientes com doença localizada, evitando assim o envelhecimento artificial da casuística.

O MC predomina nas populações brancas e principalmente em brancos caucasianos; quanto maior a exposição solar destes indivíduos, maior a sua incidência, o que claramente comprova a ação da luz solar na gênese do processo. Populações miscigenadas como a desta casuística que apresenta porcentagem considerável de pacientes não-brancos $(13,7 \%)$, nos dá a certeza de existirem outros fatores etiológicos associados à geração da doença. Populações oriundas de países com componente étnico variado apresentam-se difíceis de ser classificadas quanto à cor. Pacientes pardos poderiam ser classificados como brancos ou não-brancos. No Brasil temos dois padrões de casuística, um na região sul com predomínio de indivíduos brancos, igual ao encontrado na casuística mundial e outro, que ocorre nas outras regiões do país, sudeste, centro oeste e nordeste, onde as casuísticas apresentam 10 a 20\% de indivíduos não-brancos, na qual a casuística deste estudo se encaixa.

Cerca de $50 \%$ das lesões primárias localizaram-se nas extremidades, $30 \%$ no tronco e $20 \%$ no segmento cefálico. Para os homens ocorreu predomínio de lesões no tronco (38\%) seguido de pés $(23 \%)$ e cabeça e pescoço (19\%). Para mulheres, o local mais 
acometido foi tronco $(24,3 \%)$ seguido de pés $(21,6 \%)$ e membros inferiores $(16,8 \%)$. A maioria dos trabalhos nacionais refere-se ao predomínio nas extremidades (39 a $66 \%$ ), entretanto não distinguem mãos e pés (Bandiera e Prudente, 1967; Minelli e Pereira, 1983; Venegas et al., 1992; Fernandes et al., 1996; Giavina-Bianchi et al., 1996; Donato et al., 1997; Bernardi et al., 1998; Bakos et al., 2002; Lapa et al., 2002; Pinheiro et al., 2003; Moreno, 2005). Há relato de predomínio no tronco para homens e extremidades para mulheres (Venegas et al., 1992; Bernardi et al., 1998; Gon et al., 2001; Criado et al., 1999). Coortes recentes, provenientes de relatos internacionais, evidenciam que os locais mais acometidos para homens brancos são tronco e cabeça, sendo incomuns nas pernas. Para mulheres brancas, pernas e tronco são locais igualmente afetados (Weinstock e Mikkilinemi, 2001). Populações não-brancas têm mais lesões nas extremidades.

Na análise da localização da lesão primária em relação à cor e ao tipo de crescimento verificou-se predomínio de lesões localizadas no tronco para indivíduos brancos $(52,8 \%)$, do tipo MES $(37,6 \%)$ e MN $(27,7 \%)$ e de lesões localizadas nos pés para indivíduos nãobrancos $(68,2 \%)$, sendo $64 \%$ destes do tipo MAL. Estes dados são superponíveis ao da literatura (Reintgen et al., 1982; Seiji e 
Discussão 60

Takahashi, 1982; Chang et al., 1998; Sober e Tsao, 2003). O MAL esteve localizado predominantemente nas regiões plantares dos indivíduos não-brancos e brancos. O percentual de MAL encontrado neste estudo em indivíduos brancos $(15,6 \%)$ foi superior ao relatado na literatura (2 a 8\%) (Reintgen et al., 1982; Seiji e Takahashi, 1982). É possível que este fato relacione-se a inacurácia na distinção entre indivíduos brancos e não-brancos. Pode também decorrer que o índice de ancestralidade africana em indivíduos brancos brasileiros seja mais elevado que para outras populações brancas estudadas.

Para as mulheres predominou o MES $(37,4 \%)$. Para os homens predominou o MN (32\%) e o MES (28,7\%). Entretanto a freqüência de MAL nesta amostra foi alta, com cerca de $25 \%$ para ambos os sexos.

Nos idosos acima de 65 anos ocorreu predomínio de lesões localizadas na cabeça e pescoço $(33,3 \%)$ e pés $(27,7 \%)$ com tipos de crescimento MAL $(31,4 \%)$ e LMM $(26,7 \%)$. O predomínio de tumores localizados na cabeça e pescoço de indivíduos idosos se justifica pelo aumento da incidência de LMM nesta faixa etária. Ainda, é possível que em decorrência do diagnóstico mais tardio do MAL, o mesmo seja mais freqüente em idades avançadas. Indivíduos abaixo de 65 anos 
apresentaram predominantemente lesões localizadas no tronco $(35,4 \%)$, do tipo MES $(52,4 \%)$.

A casuística deste estudo apresentou peculiaridades em relação à localização da lesão primária e a freqüência de MAL, provavelmente em decorrência de que aproximadamente $14 \%$ dos pacientes foram não-brancos. Estes dados são comparáveis com os relatos nacionais, com pequenas variações percentuais (Fernandes et al, 1996; Brandão et al., 1998; Lapa et al., 2002; Pinheiro et al., 2003). Curiosamente este fato se repete para as populações da região sul do país, onde apesar das amostras se referirem somente a pacientes brancos, também há predomínio de MC localizados nas extremidades (Minelli e Pereira, 1983; Venegas et al., 1992; Bernardi et al., 1998; Bakos et al., 2002; Moreno, 2005).

Em relação à espessura, esta casuística revelou que as mulheres apresentaram maior proporção de MC mais finos (60\% até $2,0 \mathrm{~mm}$ ) e homens maior proporção de $M C$ espessos $(74 \%>2,0$ $\mathrm{mm}$ ), o que vai de encontro ao relatado na literatura (Dennis et al., 1999; Jemal et al., 2001; Marrett et al., 2001). Mulheres apresentaram menor proporção de lesões ulceradas. É possível que estas dediquem maior atenção a sua saúde, procurando atendimento dermatológico com maior freqüência. Os MC mais finos (até 2,0 mm) 
foram do tipo LMM e MES e aqueles mais espessos ( $>2,0 \mathrm{~mm}$ ) foram MN e MAL, comportamento esperado em decorrência dos primeiros apresentarem crescimento predominantemente radial por maiores períodos de tempo. É comum o fato do MC tipo MAL se apresentar na ocasião da primeira consulta como tumor espesso. É possível que este fato decorra de negligência por parte dos pacientes ou da não realização de diagnóstico correto por parte dos médicos.

Esta casuística ao nosso ver ainda é pequena e o período de seguimento dos pacientes insuficiente para análise de curvas de sobrevida relacionadas às diversas variáveis selecionadas. Pôde-se verificar, entretanto, que $21,2 \%$ dos pacientes com doença localizada na sua admissão evoluíram para estádios avançados. Este percentual nos pareceu elevado e deve servir de alerta e estímulo para um diagnóstico mais precoce desta neoplasia. Há referência na literatura que em torno de $20 \%$ dos pacientes com MC terão doença avançada e conseqüentemente morrerão (Mackie et al., 1995). Verificou-se também que através do cálculo da taxa de sobrevida específica para o MC, $85,1 \%$ dos pacientes com doença localizada estavam vivos em três anos. O coeficiente de letalidade para toda a amostra foi de $24,7 \%$ e para pacientes com doença localizada foi de $12,8 \%$. Uma única publicação nacional analisa taxas de sobrevida em oito anos, em 
levantamento retrospectivo de 115 pacientes (Lapa et al., 2002). Este nosso estudo proporcionou, ao longo da análise das variáveis estudadas, uma visão crítica deste banco de dados e dos trabalhos nacionais revisados. Pôde-se experimentar a dificuldade de comparação de dados pela absoluta falta de homogeneidade dos mesmos. Acreditamos que a inclusão contínua de novos casos e o seguimento adequado proporcione, em futuro próximo, estudos sobre incidência que possam ser validados estatisticamente. 
CONCLUSÕES 
1. A amostra constituiu-se de pacientes com predomínio de tumores espessos e ulcerados deduzindo-se que o diagnóstico do MC foi realizado tardiamente com conseqüente pior prognóstico. Este fato foi mais evidente em homens e idosos.

2- Em razão da composição étnica da população estudada observou-se percentual considerável de melanoma acrolentiginoso. Este predomínio levou a proporções menores dos outros tipos de crescimento, com freqüência de casos de melanoma expansivo superficial inferior à relatada na literatura internacional e na maioria das casuísticas brasileiras.

4- Observou-se percentual considerável de lesões localizadas nos pés decorrentes do expressivo percentual de MAL e de pacientes não-brancos na amostra estudada.

5- Observou-se predomínio de mulheres em praticamente todas as faixas etárias sem predomínio de lesões localizadas nas pernas como descrito na literatura. 
ANEXOS 
Anexo 1 - Protocolo informatizado da Unidade de Melanoma da Santa Casa de São Paulo.

\section{MELANOMA CUTÂNEO - GRUPO MULTIDISCIPLINAR} SANTA CASA DE MISERICÓRDIA DE SÃO PAULO

\section{IDENTIFICAÇ̃̃O}

DATA CONSULTA: (dia/mês/ano)

PROTOCOLO:

1. NOME:

2. RG:

3. IDADE:

3.1 DATANASC: (dia/mês/ano) 4. SEXO:

5. COR:

7. OCUPAÇÃO:

8. END:

FONE:

CIDADE:

ESTADO:

CEP:

\section{HISTÓRIA CLÍNICA:}

9. FATORES DE RISCO PARA MELANOMA

9.1. HISTÓRIA FAMILIAR DE MELANOMA

9.2. HISTÓRIA PESSOAL DE MELANOMA MALIGNO

9.3. FOTOTIPO DE PELE I OU II

9.4. CABELOS CLAROS (LOIROS OU RUIVOS)

9.5. OLHOS CLAROS (VERDES OU AZUIS)

9.6. NEVO MELANOCÍTICO ATÍPICO (DISPLÁSICO)

9.7. NEVO MELANOCÍTICO CONGÊNITO

9.7.1. NEVO MELANOCÍTICO TAMANHO:

9.8. NEVO MELANOCÍTICO MÚLTIPLO

9.8.1. NÚMERO DE NEVOS MELANOCÍTICOS

9.9. NEVO AZUL

9.10. NEVO OTA

9.11. PELE ACTÍNICA

9.12. RADIODERMITE CRÔNICA

9.13. QUEIMADURA SOLAR

9.14. OCUPAÇÃO INTERNA/RECREAÇÃO EXTERNA

9.15. EFÉLIDES NA INFÂNCIA 


\section{LESÃO PRIMÁRIA}

10.0. DATA LESÃO PRIMÁRIA: (dia/mês/ano)

10.1.LOCALIZAÇÃO: (LESÃO PRIMÁRIA)

10.1.1.LOCALIZAÇÃO: (SEGUNDA LESÃO PRIMÁRIA)

10.2.DIÂMETRO MAIOR:

10.3 TIPO DE LESÃO:

10.4 LESÃO ULCERADA:

10.5 LESÃO ASSIMÉTRICA:

10.6 LESÃO COM BORDA IRREGULAR:

10.7 LESÃO COM COR VARIEGADA:

10.8 LESÃO PIGMENTADA:

10.9 LESÃO COM SINAIS DE REGRESSÃO:

10.10.TUMOR PRIM. NÃO PODE SER AVALIADO:

10.11.TUMOR PRIM. NÃO FOI EVIDENCIADO:

10.12. RECIDIVA LOCAL:

10.13. LESÕES SATÉLITES:

11. TIPO DE CRESCIMENTO:

\section{DOENCCA REGIONAL}

12. LINFONODOS REGIONAIS PALPÁVEIS:

12.0. DATA: (dia/mês/ano)

12.1. LOCALIZAÇÃO: (SE PÁLPAVEL)

12.2.NÚMERO DE LINFONODOS PALPÁVEIS:

12.3. TAMANHO DOS LINFONODOS:

12.4. METÁSTASE EM TRÂNSITO:

\section{DOENCA METASTÁTICA}

14. METÁSTASES DISTANTES:

14.0.DATA: (dia/mês/ano)

14.1. METÁSTASE CUTÂNEA:

14.2. LINFONODOS À DISTÂNCIA:

14.3. METÁSTASE PULMONAR:

14.4. METÁSTASE ÓSSEA:

14.5. METÁSTASE CEREBRAL:

14.6. METÁSTASE HEPÁTICA: 
14.7. METÁSTASE PLEURA:

14.8. METÁSTASE PERITÔNEO:

14.9. OUTRAS:

15. BIÓPSIA LESÃO PRIMÁRIA:

\section{EXAME ANÁTOMO PATOLÓGICO}

16.5. SATELITOSE MICROSCÓPICA:

16.6. PRESENÇA DE INFILTRADO INFLAMATÓRIO:

16.6.1. INFILTRADO INFLAMATÓRIO:

16.7. SINAIS HISTOPATOLÓGICOS DE REGRESSÃO:

16.8. CÉLULAS NEOPLÁSICAS NA LUZ VASCULAR:

16.9. ULCERAÇÃO:

16.10. PRESENÇA DE LESÃO PRECURSORA:

16.11. NEUROTROPISMO:

17.0. DATA (dia/mês/ano)

17.3. NUM. LINFONODOS COMPROMETIDOS:

17.4. PESQUISA LINFONODO SENTINELA:

17.4..1 PESQUISA:

\section{EXAMES}

18. RX TORAX:

19. ULTRA -SOM:

20. CINTILOGRAFIA ÓSSEA:

21. TOMO CEREBRAL:

\section{ESTADIAMENTO}

24.1 MELANOMA MALIGNO ESTÁDIO:

25. CONDUTA TERAPÊUTICA:

25.1.1 DATA: (dia/mês/ano)

25.2. LESÃO PRIMÁRIA NO ESTÁDIO I - CIRURGIA:

25.4. LINFADENECTOMIA REGIONAL:

25.5. IMUNOTERAPIA POR INTERFERON:

25.6. IMUNOTERAPIA LEVAMIZOLE:

25.7. QUIMIOTERAPIA:

25.8. RADIOTERAPIA: 


\section{EVOLUCÃ̃O}

26. PRIMEIRA ALTERAÇÃO DE ESTÁDIO:

27.0. DATA (dia/mês/ano)

26.1. ESTÁDIO:

27. SEGUNDA ALTERAÇÃO DE ESTÁDIO

27.0. DATA (dia/mês/ano)

27.1. ESTÁDIO:

28. ÓBITO

29. DATA DA ÚLTIMA CONSULTA: (dia/mês/ano) 
Anexo 2A - Variáveis demográficas, clínicas e histopatológicas de 250 casos de melanoma cutâneo com doença localizada na UMSC - SP 1993 - 2006.

\begin{tabular}{cccccccccc}
\hline$N$ & $I D A D E$ & SEXO & COR & TC & LOCALI & CLARK & BRESLOW & ULCER & $p T$ \\
\hline 6 & 60 & $\mathrm{~F}$ & 1 & 1 & $\mathrm{CP}$ & 2 & 0,3 & 2 & $1 \mathrm{a}$ \\
7 & 68 & $\mathrm{~F}$ & 1 & 1 & $\mathrm{CP}$ & 1 & - & 2 & - \\
8 & 82 & $\mathrm{M}$ & 3 & 4 & $\mathrm{E}$ & 3 & 4 & 1 & $3 \mathrm{~b}$ \\
9 & 69 & $\mathrm{~F}$ & 1 & 1 & $\mathrm{CP}$ & 1 & - & 2 & - \\
10 & 74 & $\mathrm{M}$ & 1 & 1 & $\mathrm{~T}$ & 1 & - & 2 & - \\
11 & 63 & $\mathrm{~F}$ & 1 & 3 & $\mathrm{E}$ & 4 & 3 & 1 & $3 \mathrm{~b}$ \\
12 & 44 & $\mathrm{~F}$ & 1 & 2 & $\mathrm{E}$ & 1 & - & 2 & - \\
13 & 35 & $\mathrm{M}$ & 1 & 3 & $\mathrm{~T}$ & 4 & 3 & 1 & $3 \mathrm{~b}$ \\
17 & 51 & $\mathrm{~F}$ & 3 & 2 & $\mathrm{~T}$ & 2 & 0,9 & 2 & $1 \mathrm{a}$ \\
19 & 61 & $\mathrm{M}$ & 1 & 3 & $\mathrm{E}$ & 2 & 1,4 & 2 & $2 \mathrm{a}$ \\
20 & 77 & $\mathrm{~F}$ & 1 & 4 & $\mathrm{E}$ & 3 & 1 & 1 & - \\
22 & 45 & $\mathrm{~F}$ & 1 & 2 & $\mathrm{~T}$ & 2 & 0,7 & 2 & $1 \mathrm{a}$ \\
23 & 52 & $\mathrm{~F}$ & 1 & 2 & $\mathrm{CP}$ & 1 & - & 2 & - \\
27 & 85 & $\mathrm{M}$ & 1 & 3 & $\mathrm{CP}$ & 4 & 3,5 & 1 & $3 \mathrm{~b}$ \\
29 & 21 & $\mathrm{~F}$ & 1 & 3 & $\mathrm{E}$ & 4 & 1 & 1 & $1 \mathrm{~b}$ \\
33 & 68 & $\mathrm{M}$ & 1 & 4 & $\mathrm{E}$ & 5 & 13 & 1 & $4 \mathrm{~b}$ \\
34 & 58 & $\mathrm{~F}$ & 1 & 2 & $\mathrm{E}$ & 3 & 0,8 & 2 & $1 \mathrm{a}$ \\
35 & 65 & $\mathrm{~F}$ & 3 & 4 & $\mathrm{E}$ & 1 & - & 2 & - \\
37 & 51 & $\mathrm{~F}$ & 1 & 4 & $\mathrm{E}$ & 5 & 18 & 2 & $4 \mathrm{a}$ \\
39 & 56 & $\mathrm{~F}$ & 1 & 4 & $\mathrm{E}$ & 1 & - & 2 & - \\
43 & 44 & $\mathrm{~F}$ & 1 & 2 & $\mathrm{CP}$ & 3 & 0,3 & 2 & $1 \mathrm{a}$ \\
47 & 61 & $\mathrm{~F}$ & 1 & 3 & $\mathrm{E}$ & 2 & 0,3 & 1 & $1 \mathrm{~b}$ \\
49 & 38 & $\mathrm{~F}$ & 1 & 3 & $\mathrm{~T}$ & 3 & 0,8 & 2 & $1 \mathrm{a}$ \\
50 & 54 & $\mathrm{~F}$ & 1 & 3 & $\mathrm{E}$ & 4 & 3 & 2 & $2 \mathrm{a}$ \\
51 & 44 & $\mathrm{M}$ & 1 & 4 & $\mathrm{E}$ & 3 & 1,39 & 1 & $2 \mathrm{~b}$ \\
53 & 33 & $\mathrm{~F}$ & 1 & 3 & $\mathrm{~T}$ & 2 & 0,3 & 2 & $1 \mathrm{a}$ \\
54 & 56 & $\mathrm{~F}$ & 1 & 4 & $\mathrm{E}$ & 3 & 1,6 & 2 & $2 \mathrm{a}$ \\
55 & 71 & $\mathrm{~F}$ & 1 & 2 & $\mathrm{E}$ & 3 & 0,75 & 2 & $1 \mathrm{a}$ \\
56 & 72 & $\mathrm{M}$ & 1 & 1 & $\mathrm{~T}$ & 1 & - & 2 & - \\
57 & 60 & $\mathrm{~F}$ & 1 & 2 & $\mathrm{~T}$ & 4 & 3,2 & 1 & $3 \mathrm{~b}$ \\
58 & 65 & $\mathrm{M}$ & 1 & 4 & $\mathrm{E}$ & 4 & 10 & 1 & $4 \mathrm{~b}$ \\
59 & 27 & $\mathrm{~F}$ & 1 & 2 & $\mathrm{~T}$ & 4 & 1,5 & 1 & $2 \mathrm{~b}$ \\
61 & 71 & $\mathrm{M}$ & 1 & 4 & $\mathrm{E}$ & 5 & 4 & 1 & $3 \mathrm{~b}$ \\
62 & 37 & $\mathrm{M}$ & 1 & 3 & $\mathrm{~T}$ & 4 & 3 & 2 & $3 \mathrm{a}$ \\
63 & 75 & $\mathrm{~F}$ & 1 & 4 & $\mathrm{E}$ & 5 & 4,5 & 1 & $4 \mathrm{~b}$ \\
64 & 41 & $\mathrm{~F}$ & 1 & 3 & $\mathrm{CP}$ & 3 & 2 & 2 & $2 \mathrm{a}$ \\
65 & 72 & $\mathrm{~F}$ & 1 & 1 & $\mathrm{CP}$ & 1 & - & 2 & - \\
68 & 66 & $\mathrm{~F}$ & 1 & 4 & $\mathrm{E}$ & 4 & 5 & 2 & $4 \mathrm{a}$ \\
70 & 54 & $\mathrm{~F}$ & 1 & 4 & $\mathrm{E}$ & 4 & 4,7 & 1 & $4 \mathrm{~b}$ \\
71 & 21 & $\mathrm{~F}$ & 1 & 3 & $\mathrm{CP}$ & 4 & 1,8 & 1 & $2 \mathrm{~b}$ \\
& & & & & & & & $\mathrm{Continua}$ \\
& & & & & & & &
\end{tabular}


Continuação: Anexo 2A - Variáveis demográficas, clínicas e histopatológicas de 250

casos de melanoma cutâneo com doença localizada na UMSC - SP 1993 - 2006.

\begin{tabular}{cccccccccc}
\hline$N$ & IDADE & SEXO & COR & TC & LOCALI & CLARK & BRESLOW & ULCER & $p T$ \\
72 & 62 & $\mathrm{M}$ & 1 & 3 & $\mathrm{~T}$ & 3 & 15 & 1 & $4 \mathrm{~b}$ \\
74 & 77 & $\mathrm{~F}$ & 1 & 4 & $\mathrm{E}$ & 4 & 8 & 1 & $4 \mathrm{~b}$ \\
76 & 52 & $\mathrm{~F}$ & 1 & 2 & $\mathrm{E}$ & 1 & - & 2 & - \\
77 & 75 & $\mathrm{M}$ & 1 & 4 & $\mathrm{E}$ & 5 & 25 & 1 & $4 \mathrm{~b}$ \\
79 & 77 & $\mathrm{~F}$ & 1 & 2 & $\mathrm{~T}$ & 2 & 0,75 & 2 & $1 \mathrm{a}$ \\
80 & 27 & $\mathrm{~F}$ & 1 & 3 & $\mathrm{E}$ & 4 & 3 & 2 & $3 \mathrm{a}$ \\
81 & 77 & $\mathrm{M}$ & 1 & 3 & $\mathrm{CP}$ & 5 & 5 & 1 & $4 \mathrm{~b}$ \\
82 & 63 & $\mathrm{~F}$ & 3 & 2 & $\mathrm{~T}$ & 1 & - & 2 & - \\
83 & 52 & $\mathrm{~F}$ & 3 & 4 & $\mathrm{E}$ & 4 & 5 & 1 & $4 \mathrm{~b}$ \\
85 & 63 & $\mathrm{~F}$ & 1 & 2 & $\mathrm{~T}$ & 2 & 0,7 & 2 & $1 \mathrm{a}$ \\
87 & 38 & $\mathrm{~F}$ & 1 & 2 & $\mathrm{E}$ & 3 & 1,25 & 2 & $2 \mathrm{a}$ \\
90 & 48 & $\mathrm{~F}$ & 1 & 2 & $\mathrm{~T}$ & 2 & 0,75 & 2 & $1 \mathrm{a}$ \\
91 & 60 & $\mathrm{~F}$ & 2 & 4 & $\mathrm{E}$ & 4 & 10 & 1 & $4 \mathrm{~b}$ \\
92 & 16 & $\mathrm{~F}$ & 1 & 2 & $\mathrm{~T}$ & 1 & - & 2 & - \\
96 & 76 & $\mathrm{~F}$ & 1 & 2 & $\mathrm{~T}$ & 2 & 0,75 & 2 & $1 \mathrm{a}$ \\
98 & 47 & $\mathrm{~F}$ & 1 & 2 & $\mathrm{E}$ & 4 & 3 & 1 & $3 \mathrm{~b}$ \\
100 & 50 & $\mathrm{~F}$ & 1 & 2 & $\mathrm{~T}$ & 1 & - & 2 & - \\
102 & 68 & $\mathrm{M}$ & 1 & 1 & $\mathrm{CP}$ & 1 & - & 2 & - \\
103 & 55 & $\mathrm{M}$ & 1 & 2 & $\mathrm{~T}$ & 2 & 0,75 & 2 & $1 \mathrm{a}$ \\
104 & 30 & $\mathrm{~F}$ & 1 & 2 & $\mathrm{CP}$ & 2 & 0,7 & 2 & $1 \mathrm{a}$ \\
105 & 57 & $\mathrm{M}$ & 1 & 1 & $\mathrm{~T}$ & 4 & 4 & 1 & $3 \mathrm{~b}$ \\
106 & 65 & $\mathrm{~F}$ & 1 & 1 & $\mathrm{CP}$ & 1 & - & 2 & - \\
107 & 52 & $\mathrm{~F}$ & 1 & 3 & $\mathrm{~T}$ & 5 & 6,9 & 2 & $4 \mathrm{a}$ \\
108 & 78 & $\mathrm{~F}$ & 2 & 4 & $\mathrm{E}$ & 5 & 10 & 1 & $4 \mathrm{~b}$ \\
109 & 54 & $\mathrm{~F}$ & 1 & 2 & $\mathrm{~T}$ & 1 & - & 2 & - \\
110 & 74 & $\mathrm{~F}$ & 1 & 1 & $\mathrm{CP}$ & 1 & - & 2 & - \\
111 & 30 & $\mathrm{~F}$ & 1 & 2 & $\mathrm{~T}$ & 2 & 1,3 & 2 & $2 \mathrm{a}$ \\
112 & 58 & $\mathrm{M}$ & 1 & 4 & $\mathrm{E}$ & 2 & 1,4 & 2 & $2 \mathrm{a}$ \\
113 & 61 & $\mathrm{M}$ & 1 & 2 & - & 3 & 3 & 2 & $3 \mathrm{a}$ \\
114 & 48 & $\mathrm{~F}$ & 1 & 1 & $\mathrm{E}$ & 2 & 0,75 & 2 & $1 \mathrm{a}$ \\
115 & 65 & $\mathrm{M}$ & 1 & 1 & $\mathrm{CP}$ & 2 & 2 & 2 & $2 \mathrm{a}$ \\
116 & 82 & $\mathrm{M}$ & 3 & 4 & $\mathrm{E}$ & 3 & 2,6 & 1 & $3 \mathrm{~b}$ \\
119 & 71 & $\mathrm{~F}$ & 1 & 2 & $\mathrm{~T}$ & 4 & 2 & 2 & $2 \mathrm{a}$ \\
120 & 71 & $\mathrm{M}$ & 1 & 1 & $\mathrm{CP}$ & 1 & - & 2 & - \\
121 & 47 & $\mathrm{~F}$ & 1 & 2 & $\mathrm{~T}$ & 3 & 1 & 2 & $1 \mathrm{a}$ \\
122 & 41 & $\mathrm{~F}$ & 1 & 2 & $\mathrm{E}$ & 2 & 0,5 & 2 & $1 \mathrm{a}$ \\
124 & 71 & $\mathrm{~F}$ & 1 & 4 & $\mathrm{E}$ & 1 & - & 2 & - \\
125 & 79 & $\mathrm{M}$ & 1 & 1 & $\mathrm{CP}$ & 1 & 0,2 & 2 & - \\
126 & 63 & $\mathrm{M}$ & 1 & 3 & $\mathrm{CP}$ & 4 & 4,5 & 1 & $4 \mathrm{~b}$ \\
127 & 79 & $\mathrm{~F}$ & 1 & 3 & $\mathrm{CP}$ & 4 & 8 & 1 & $4 \mathrm{~b}$ \\
& & & & & & & & $\mathrm{Continua}$ \\
& & & & & & & & &
\end{tabular}


Continuação: Anexo 2A - Variáveis demográficas, clínicas e histopatológicas de 250

casos de melanoma cutâneo com doença localizada na UMSC - SP 1993 - 2006.

\begin{tabular}{cccccccccc}
\hline$N$ & IDADE & SEXO & $C O R$ & TC & LOCALI & CLARK & BRESLOW & ULCER & $p T$ \\
128 & 57 & $\mathrm{M}$ & 1 & 1 & $\mathrm{CP}$ & 1 & - & 2 & - \\
129 & 57 & $\mathrm{~F}$ & 1 & 2 & $\mathrm{E}$ & 2 & 0,75 & 2 & $1 \mathrm{a}$ \\
130 & 55 & $\mathrm{~F}$ & 3 & 1 & $\mathrm{CP}$ & 1 & - & 2 & - \\
131 & 63 & $\mathrm{M}$ & 1 & 3 & $\mathrm{E}$ & 4 & 10 & 2 & $4 \mathrm{a}$ \\
132 & 77 & $\mathrm{~F}$ & 1 & 3 & $\mathrm{~T}$ & 3 & 10 & 1 & $4 \mathrm{~b}$ \\
133 & 80 & $\mathrm{M}$ & 1 & 2 & $\mathrm{~T}$ & 3 & 4 & 1 & $3 \mathrm{~b}$ \\
135 & 74 & $\mathrm{~F}$ & 1 & 3 & $\mathrm{CP}$ & 5 & 9 & 1 & $4 \mathrm{~b}$ \\
136 & 49 & $\mathrm{M}$ & 1 & 2 & $\mathrm{~T}$ & 3 & 1,5 & 1 & $2 \mathrm{~b}$ \\
137 & 69 & $\mathrm{~F}$ & 1 & 1 & $\mathrm{CP}$ & 1 & - & 2 & - \\
138 & 77 & $\mathrm{~F}$ & 1 & 4 & $\mathrm{E}$ & 5 & 10 & 1 & $4 \mathrm{~b}$ \\
139 & 44 & $\mathrm{M}$ & 2 & 4 & $\mathrm{E}$ & 4 & 1,2 & 2 & $2 \mathrm{a}$ \\
140 & 33 & $\mathrm{~F}$ & 1 & 2 & $\mathrm{CP}$ & 3 & 2 & 2 & $2 \mathrm{a}$ \\
141 & 91 & $\mathrm{M}$ & 1 & 4 & $\mathrm{E}$ & 5 & 10 & 1 & $4 \mathrm{~b}$ \\
142 & 41 & $\mathrm{~F}$ & 1 & 2 & $\mathrm{E}$ & 4 & 1 & 2 & $1 \mathrm{~b}$ \\
143 & 67 & $\mathrm{M}$ & 1 & 2 & $\mathrm{E}$ & 4 & 15 & 1 & $4 \mathrm{~b}$ \\
144 & 39 & $\mathrm{~F}$ & 1 & 1 & $\mathrm{CP}$ & 3 & 1,3 & 2 & $2 \mathrm{a}$ \\
145 & 26 & $\mathrm{~F}$ & 1 & 2 & $\mathrm{E}$ & 3 & 1,4 & 2 & $2 \mathrm{a}$ \\
146 & 49 & $\mathrm{M}$ & 1 & 3 & $\mathrm{CP}$ & 4 & 6 & 2 & $4 \mathrm{a}$ \\
148 & 62 & $\mathrm{~F}$ & 2 & 4 & $\mathrm{E}$ & 1 & - & 2 & - \\
150 & 59 & $\mathrm{M}$ & 4 & 4 & $\mathrm{E}$ & 4 & 3 & 2 & $3 \mathrm{a}$ \\
151 & 72 & $\mathrm{~F}$ & 1 & 4 & $\mathrm{E}$ & 5 & 10 & 1 & $4 \mathrm{~b}$ \\
155 & 54 & $\mathrm{M}$ & 1 & 2 & $\mathrm{~T}$ & - & - & - & - \\
156 & 33 & $\mathrm{M}$ & 1 & 3 & $\mathrm{~T}$ & 5 & 10 & 1 & $4 \mathrm{~b}$ \\
157 & 28 & $\mathrm{~F}$ & 1 & 2 & $\mathrm{~T}$ & 3 & 0,2 & 2 & $1 \mathrm{a}$ \\
158 & 40 & $\mathrm{~F}$ & 1 & 2 & $\mathrm{E}$ & 3 & 1 & 2 & $1 \mathrm{a}$ \\
159 & 76 & $\mathrm{~F}$ & 1 & 4 & $\mathrm{E}$ & 4 & 1,5 & 1 & $2 \mathrm{~b}$ \\
161 & 66 & $\mathrm{~F}$ & 1 & 5 & $\mathrm{E}$ & 5 & 25 & 2 & $4 \mathrm{a}$ \\
162 & 59 & $\mathrm{M}$ & 1 & 3 & $\mathrm{~T}$ & 4 & 5 & 2 & $4 \mathrm{a}$ \\
163 & 67 & $\mathrm{M}$ & 2 & 4 & $\mathrm{E}$ & 4 & 4 & 1 & $3 \mathrm{~b}$ \\
164 & 57 & $\mathrm{~F}$ & 3 & 3 & $\mathrm{E}$ & 5 & 6 & 2 & $4 \mathrm{a}$ \\
165 & 71 & $\mathrm{~F}$ & 1 & 4 & $\mathrm{E}$ & 3 & 1 & 1 & $1 \mathrm{~b}$ \\
169 & 34 & $\mathrm{~F}$ & 1 & 3 & $\mathrm{E}$ & 4 & 3 & 1 & $3 \mathrm{~b}$ \\
171 & 87 & $\mathrm{~F}$ & 1 & 2 & $\mathrm{E}$ & 5 & 6 & 2 & $4 \mathrm{a}$ \\
173 & 67 & $\mathrm{~F}$ & 1 & 2 & $\mathrm{E}$ & 5 & 5 & 2 & $4 \mathrm{a}$ \\
174 & 28 & $\mathrm{~F}$ & 1 & 2 & $\mathrm{E}$ & 1 & - & 2 & - \\
175 & 69 & $\mathrm{M}$ & 1 & 2 & $\mathrm{~T}$ & 3 & 1,6 & 2 & $2 \mathrm{a}$ \\
176 & 69 & $\mathrm{~F}$ & 1 & 2 & $\mathrm{~T}$ & 1 & - & 2 & - \\
177 & 30 & $\mathrm{M}$ & 3 & 4 & $\mathrm{E}$ & 4 & 35 & 1 & $4 \mathrm{~b}$ \\
179 & 71 & $\mathrm{~F}$ & 1 & 1 & $\mathrm{E}$ & 3 & 1,9 & 2 & $2 \mathrm{a}$ \\
180 & 44 & $\mathrm{M}$ & 1 & 3 & $\mathrm{~T}$ & 2 & 10 & 1 & $4 \mathrm{~b}$ \\
& & & & & & & & $\mathrm{Continua}$ \\
& & & & & & & &
\end{tabular}


Continuação: Anexo 2A - Variáveis demográficas, clínicas e histopatológicas de 250 casos de melanoma cutâneo com doença localizada na UMSC - SP 1993 - 2006.

\begin{tabular}{cccccccccc}
\hline$N$ & IDADE & SEXO & COR & TC & LOCALI & CLARK & BRESLOW & ULCER & $p T$ \\
181 & 74 & $\mathrm{~F}$ & 1 & 2 & $\mathrm{~T}$ & 3 & 3 & 1 & $3 \mathrm{~b}$ \\
183 & 69 & $\mathrm{M}$ & 1 & 4 & $\mathrm{E}$ & 2 & 1 & 1 & $1 \mathrm{~b}$ \\
187 & 67 & $\mathrm{~F}$ & 1 & 2 & $\mathrm{E}$ & 3 & 0,76 & 2 & $1 \mathrm{a}$ \\
188 & 68 & $\mathrm{~F}$ & 1 & 2 & $\mathrm{~T}$ & 3 & 0,75 & 2 & $1 \mathrm{a}$ \\
189 & 70 & $\mathrm{~F}$ & 1 & 1 & $\mathrm{~T}$ & 5 & 5 & 2 & $4 \mathrm{a}$ \\
190 & 60 & $\mathrm{~F}$ & 1 & 2 & $\mathrm{E}$ & 2 & 0,75 & 2 & $1 \mathrm{a}$ \\
191 & 91 & $\mathrm{~F}$ & 1 & 1 & $\mathrm{CP}$ & 4 & 5 & 1 & $4 \mathrm{~b}$ \\
194 & 27 & $\mathrm{~F}$ & 1 & 2 & $\mathrm{~T}$ & 4 & 4,2 & 2 & $4 \mathrm{a}$ \\
195 & 68 & $\mathrm{M}$ & 1 & 3 & $\mathrm{E}$ & 4 & 3,2 & 2 & $3 \mathrm{a}$ \\
196 & 70 & $\mathrm{~F}$ & 1 & 2 & $\mathrm{~T}$ & 1 & - & 2 & - \\
197 & 78 & $\mathrm{M}$ & 2 & 4 & $\mathrm{E}$ & 3 & 0,46 & 1 & $1 \mathrm{~b}$ \\
198 & 57 & $\mathrm{M}$ & 1 & 4 & $\mathrm{E}$ & 4 & 4 & 1 & $3 \mathrm{~b}$ \\
200 & 21 & $\mathrm{~F}$ & 2 & 3 & $\mathrm{~T}$ & 3 & 4,4 & 1 & $4 \mathrm{~b}$ \\
201 & 41 & $\mathrm{~F}$ & 1 & 2 & $\mathrm{~T}$ & 1 & - & 2 & - \\
202 & 64 & $\mathrm{M}$ & 1 & 2 & $\mathrm{CP}$ & 2 & 0,76 & 2 & $1 \mathrm{a}$ \\
203 & 33 & $\mathrm{M}$ & 1 & 2 & $\mathrm{~T}$ & 4 & 1,6 & 2 & $2 \mathrm{a}$ \\
204 & 27 & $\mathrm{M}$ & 1 & 2 & $\mathrm{~T}$ & 2 & 0,7 & 2 & $1 \mathrm{a}$ \\
205 & 36 & $\mathrm{~F}$ & 1 & 2 & $\mathrm{E}$ & 3 & 1,2 & 2 & $2 \mathrm{a}$ \\
208 & 65 & $\mathrm{M}$ & 1 & 2 & $\mathrm{E}$ & 3 & 7 & 1 & $4 \mathrm{~b}$ \\
209 & 88 & $\mathrm{~F}$ & 1 & 3 & $\mathrm{~T}$ & 4 & 3,96 & 1 & $3 \mathrm{~b}$ \\
210 & 78 & $\mathrm{M}$ & 1 & 3 & $\mathrm{CP}$ & 4 & 1,3 & 2 & $2 \mathrm{a}$ \\
211 & 73 & $\mathrm{M}$ & 1 & 4 & $\mathrm{E}$ & 4 & 8 & 1 & $4 \mathrm{~b}$ \\
212 & 48 & $\mathrm{~F}$ & 1 & 2 & $\mathrm{E}$ & 4 & 2 & 2 & $2 \mathrm{a}$ \\
213 & 47 & $\mathrm{~F}$ & 1 & 3 & $\mathrm{E}$ & 4 & 6 & 1 & $4 \mathrm{~b}$ \\
215 & 76 & $\mathrm{M}$ & 1 & 1 & $\mathrm{~T}$ & 1 & - & 2 & - \\
216 & 73 & $\mathrm{~F}$ & 1 & 3 & $\mathrm{E}$ & 5 & 4 & 2 & $3 \mathrm{a}$ \\
217 & 65 & $\mathrm{~F}$ & 1 & 2 & $\mathrm{CP}$ & 3 & 1 & 2 & $1 \mathrm{a}$ \\
218 & 70 & $\mathrm{~F}$ & 1 & 2 & $\mathrm{E}$ & 1 & - & 2 & - \\
219 & 50 & $\mathrm{~F}$ & 1 & 2 & $\mathrm{~T}$ & 2 & 0,75 & 2 & $1 \mathrm{a}$ \\
221 & 78 & $\mathrm{M}$ & 1 & 1 & $\mathrm{CP}$ & 1 & - & 2 & - \\
222 & 62 & $\mathrm{M}$ & 1 & 2 & $\mathrm{E}$ & 4 & 0,9 & 2 & $1 \mathrm{~b}$ \\
224 & 57 & $\mathrm{M}$ & 1 & 4 & $\mathrm{E}$ & 4 & 5 & 2 & $4 \mathrm{a}$ \\
228 & 56 & $\mathrm{M}$ & 1 & 2 & $\mathrm{~T}$ & 3 & 4 & 1 & $3 \mathrm{~b}$ \\
229 & 47 & $\mathrm{~F}$ & 3 & 2 & $\mathrm{E}$ & 3 & 5 & 1 & $4 \mathrm{~b}$ \\
230 & 44 & $\mathrm{M}$ & 3 & 4 & $\mathrm{E}$ & 1 & - & 2 & - \\
231 & 76 & $\mathrm{~F}$ & 2 & 4 & $\mathrm{E}$ & 3 & 1 & 1 & $1 \mathrm{~b}$ \\
232 & 78 & $\mathrm{M}$ & 1 & 2 & $\mathrm{CP}$ & 1 & - & 2 & - \\
233 & 60 & $\mathrm{~F}$ & 1 & 1 & $\mathrm{E}$ & 1 & - & 2 & - \\
235 & 41 & $\mathrm{~F}$ & 1 & 2 & $\mathrm{~T}$ & 3 & 1,4 & 2 & $2 \mathrm{a}$ \\
238 & 83 & $\mathrm{M}$ & 1 & 1 & $\mathrm{CP}$ & 1 & - & 2 & - \\
& & & & & & & & $\mathrm{Continua}$ \\
& & & & & & & & &
\end{tabular}


Continuação: Anexo 2A - Variáveis demográficas, clínicas e histopatológicas de 250 casos de melanoma cutâneo com doença localizada na UMSC - SP 1993 - 2006.

\begin{tabular}{|c|c|c|c|c|c|c|c|c|c|}
\hline$N$ & $I D A D E$ & SEXO & $C O R$ & $T C$ & LOCALI & CLARK & BRESLOW & ULCER & $p T$ \\
\hline 239 & 54 & M & 1 & 2 & $\mathrm{~T}$ & 4 & 3 & 2 & $3 a$ \\
\hline 240 & 72 & $F$ & 1 & 1 & $\mathrm{CP}$ & 1 & - & 2 & \\
\hline 241 & 80 & $F$ & 1 & 2 & $E$ & 1 & - & 2 & \\
\hline 242 & 41 & $F$ & 1 & 3 & $E$ & 3 & 1 & 2 & 1 \\
\hline 243 & 79 & $M$ & 1 & 3 & $\mathrm{CP}$ & 3 & 5 & 2 & 47 \\
\hline 244 & 58 & $F$ & 1 & 2 & E & 3 & 1,5 & 2 & \\
\hline 245 & 73 & $F$ & 1 & 2 & $\mathrm{~T}$ & 3 & 1,5 & 2 & \\
\hline 246 & 38 & $F$ & 1 & 2 & $E$ & 2 & 2 & 1 & \\
\hline 247 & 63 & $F$ & 1 & 4 & $E$ & 4 & 2 & 2 & \\
\hline 249 & 74 & $F$ & 1 & 3 & $E$ & 5 & 5 & 2 & \\
\hline 250 & 42 & $F$ & 1 & 2 & $E$ & 4 & 2 & 2 & \\
\hline 252 & 90 & $F$ & 1 & 4 & $E$ & 3 & 6 & 1 & \\
\hline 254 & 61 & $F$ & 2 & 3 & $E$ & 4 & 3 & 1 & \\
\hline 255 & 44 & $F$ & 1 & 3 & $E$ & 4 & 5 & 1 & \\
\hline 256 & 71 & $F$ & 1 & 3 & CP & 5 & 10 & 1 & \\
\hline 257 & 67 & $F$ & 1 & 1 & $\mathrm{CP}$ & 3 & 0,2 & 2 & \\
\hline 258 & 72 & $M$ & 1 & 1 & $E$ & 1 & - & 2 & \\
\hline 259 & 50 & $F$ & 1 & 3 & $E$ & 3 & 7 & 2 & \\
\hline 261 & 88 & $M$ & 1 & 1 & $\mathrm{CP}$ & 3 & 2 & 2 & \\
\hline 262 & 66 & M & 1 & 3 & $\mathrm{CP}$ & 4 & 4 & 1 & \\
\hline 263 & 45 & $F$ & 1 & 2 & CP & 2 & 1 & 2 & \\
\hline 264 & 30 & $M$ & 1 & 2 & $\mathrm{~T}$ & 4 & 1 & 2 & \\
\hline 265 & 66 & $F$ & 1 & 2 & $E$ & 3 & 1 & 2 & \\
\hline 266 & 72 & M & 1 & 2 & $\mathrm{~T}$ & 1 & - & 2 & \\
\hline 267 & 69 & $F$ & 1 & 4 & $E$ & 2 & 0,5 & 2 & \\
\hline 269 & 61 & $F$ & 1 & 1 & $\mathrm{CP}$ & 1 & - & 2 & \\
\hline 270 & 61 & M & 1 & 3 & CP & 4 & 1,5 & 1 & \\
\hline 273 & 88 & $M$ & 1 & 3 & $E$ & 4 & 9 & 1 & \\
\hline 274 & 83 & M & 1 & 3 & E & 5 & 15 & 1 & \\
\hline 275 & 69 & $\mathrm{~F}$ & 1 & 1 & CP & 2 & 1 & 2 & \\
\hline 276 & 72 & $F$ & 1 & 5 & $\mathrm{CP}$ & 4 & 1 & 2 & \\
\hline 277 & 65 & $M$ & 1 & 3 & $\mathrm{~T}$ & 3 & 13 & 1 & \\
\hline 279 & 81 & $F$ & 1 & 4 & $E$ & 1 & - & 2 & \\
\hline 280 & 77 & $M$ & 1 & 4 & E & 3 & 4 & 1 & \\
\hline 283 & 63 & $F$ & 3 & 4 & E & 5 & 8 & 1 & \\
\hline 285 & 42 & $\mathrm{~F}$ & 1 & 2 & $\mathrm{CP}$ & 2 & 1 & 2 & \\
\hline 286 & 68 & $F$ & 1 & 4 & E & 5 & 10 & 1 & \\
\hline 287 & 70 & M & 1 & 4 & $\mathrm{E}$ & 5 & 10 & 1 & \\
\hline 289 & 81 & $F$ & 3 & 1 & $\mathrm{CP}$ & 2 & 0,6 & 2 & \\
\hline 290 & 47 & $\mathrm{~F}$ & 1 & 2 & E & 2 & 1 & 2 & \\
\hline
\end{tabular}


Continuação: Anexo 2A - Variáveis demográficas, clínicas e histopatológicas de 250 casos de melanoma cutâneo com doença localizada na UMSC - SP 1993 - 2006.

\begin{tabular}{cccccccccc}
\hline$N$ & $I D A D E$ & SEXO & $C O R$ & $T C$ & LOCALI & CLARK & BRESLOW & ULCER & PT \\
291 & 46 & $\mathrm{M}$ & 1 & 3 & $\mathrm{~T}$ & 4 & 10 & 1 & $4 \mathrm{~b}$ \\
292 & 94 & $\mathrm{~F}$ & 3 & 4 & $\mathrm{E}$ & 5 & 20 & 1 & $4 \mathrm{~b}$ \\
293 & 71 & $\mathrm{M}$ & 1 & 4 & $\mathrm{E}$ & 4 & 2,5 & 1 & $3 \mathrm{~b}$ \\
294 & 35 & $\mathrm{~F}$ & 1 & 2 & $\mathrm{E}$ & 2 & 1 & 2 & $1 \mathrm{a}$ \\
295 & 70 & $\mathrm{~F}$ & 1 & 2 & $\mathrm{E}$ & 3 & 2,1 & 2 & $3 \mathrm{a}$ \\
296 & 71 & $\mathrm{~F}$ & 1 & 1 & $\mathrm{CP}$ & 2 & 1 & 2 & $1 \mathrm{a}$ \\
297 & 62 & $\mathrm{M}$ & 1 & 2 & $\mathrm{~T}$ & 4 & 3 & 1 & $3 \mathrm{~b}$ \\
299 & 61 & $\mathrm{~F}$ & 3 & 4 & $\mathrm{E}$ & 1 & - & 2 & - \\
300 & 35 & $\mathrm{M}$ & 1 & 2 & $\mathrm{E}$ & 2 & 0,2 & 2 & $1 \mathrm{a}$ \\
301 & 56 & $\mathrm{~F}$ & 1 & 2 & $\mathrm{~T}$ & 2 & 0,5 & 2 & $1 \mathrm{a}$ \\
302 & 49 & $\mathrm{M}$ & 1 & 2 & $\mathrm{E}$ & 4 & 5 & 2 & $4 \mathrm{a}$ \\
303 & 60 & $\mathrm{~F}$ & 1 & 1 & $\mathrm{E}$ & 1 & - & 2 & - \\
305 & 60 & $\mathrm{M}$ & 1 & 2 & $\mathrm{E}$ & 2 & - & - & - \\
306 & 63 & $\mathrm{~F}$ & 1 & 4 & $\mathrm{E}$ & 4 & 4 & 2 & $3 \mathrm{a}$ \\
307 & 67 & $\mathrm{M}$ & 1 & 3 & $\mathrm{CP}$ & 3 & 3 & 1 & $3 \mathrm{~b}$ \\
308 & 48 & $\mathrm{~F}$ & 1 & 2 & $\mathrm{E}$ & 1 & - & 2 & - \\
312 & 60 & $\mathrm{M}$ & 1 & 2 & $\mathrm{E}$ & 1 & - & 2 & - \\
315 & 82 & $\mathrm{~F}$ & 1 & 3 & $\mathrm{CP}$ & 5 & 10 & 1 & $4 \mathrm{~b}$ \\
316 & 48 & $\mathrm{M}$ & 3 & 4 & $\mathrm{E}$ & 5 & 5 & 1 & $4 \mathrm{~b}$ \\
317 & 61 & $\mathrm{~F}$ & 1 & 3 & $\mathrm{CP}$ & 4 & 4 & 2 & $3 \mathrm{a}$ \\
318 & 62 & $\mathrm{M}$ & 1 & 2 & $\mathrm{CP}$ & 3 & 1 & 2 & $1 \mathrm{a}$ \\
319 & 61 & $\mathrm{M}$ & 1 & 3 & $\mathrm{~T}$ & 3 & 7 & 1 & $4 \mathrm{~b}$ \\
320 & 59 & $\mathrm{M}$ & 1 & 1 & $\mathrm{CP}$ & 1 & - & 2 & - \\
323 & 77 & $\mathrm{~F}$ & 1 & 1 & $\mathrm{CP}$ & 1 & - & 2 & - \\
325 & 41 & $\mathrm{M}$ & 1 & 2 & $\mathrm{~T}$ & 2 & 2,6 & 2 & $3 \mathrm{a}$ \\
327 & 59 & $\mathrm{M}$ & 1 & 2 & $\mathrm{~T}$ & 1 & - & 2 & - \\
328 & 43 & $\mathrm{~F}$ & 1 & 2 & $\mathrm{~T}$ & 1 & - & 2 & - \\
329 & 36 & $\mathrm{~F}$ & 1 & 2 & $\mathrm{E}$ & 2 & 0,3 & 2 & $1 \mathrm{a}$ \\
330 & 30 & $\mathrm{~F}$ & 1 & 2 & $\mathrm{E}$ & 1 & - & 2 & - \\
331 & 40 & $\mathrm{~F}$ & 1 & 2 & $\mathrm{E}$ & 4 & 10 & 1 & $4 \mathrm{~b}$ \\
332 & 28 & $\mathrm{M}$ & 1 & 2 & $\mathrm{E}$ & 2 & 1 & 2 & $1 \mathrm{a}$ \\
333 & 39 & $\mathrm{~F}$ & 3 & 4 & $\mathrm{E}$ & 3 & 1,5 & 2 & $2 \mathrm{a}$ \\
335 & 35 & $\mathrm{~F}$ & 1 & 3 & $\mathrm{~T}$ & 5 & 12 & 1 & $4 \mathrm{~b}$ \\
336 & 62 & $\mathrm{M}$ & 3 & 2 & $\mathrm{~T}$ & 2 & 1 & 2 & $1 \mathrm{a}$ \\
338 & 54 & $\mathrm{M}$ & 3 & 4 & $\mathrm{E}$ & 5 & - & - & - \\
342 & 68 & $\mathrm{~F}$ & 3 & 4 & $\mathrm{E}$ & 2 & 2 & 2 & $2 \mathrm{a}$ \\
344 & 41 & $\mathrm{~F}$ & 1 & 2 & $\mathrm{~T}$ & 3 & 2 & 1 & $2 \mathrm{~b}$ \\
346 & 79 & $\mathrm{~F}$ & 1 & 1 & $\mathrm{CP}$ & 1 & - & 2 & - \\
347 & 65 & $\mathrm{M}$ & 1 & 3 & $\mathrm{E}$ & - & - & - & - \\
349 & 52 & $\mathrm{~F}$ & 3 & 2 & $\mathrm{CP}$ & 3 & 3,1 & 2 & $3 \mathrm{a}$ \\
351 & 61 & $\mathrm{~F}$ & 1 & 1 & $\mathrm{~T}$ & 1 & - & 2 & - \\
& & & & & & & & $\mathrm{Continua}$
\end{tabular}


Conclusão: Anexo 2A - Variáveis demográficas, clínicas e histopatológicas de 250 casos de melanoma cutâneo com doença localizada na UMSC - SP 1993 - 2006.

\begin{tabular}{cccccccccc}
\hline$N$ & IDADE & SEXO & COR & TC & LOCALI & CLARK & BRESLOW & ULCER & $p T$ \\
352 & 69 & $\mathrm{~F}$ & 1 & 4 & $\mathrm{E}$ & 4 & 1,6 & 2 & $2 \mathrm{a}$ \\
353 & 59 & $\mathrm{~F}$ & 1 & 1 & $\mathrm{~T}$ & - & - & - & - \\
354 & 55 & $\mathrm{M}$ & 1 & 2 & $\mathrm{~T}$ & 4 & 1,5 & 2 & $2 \mathrm{a}$ \\
355 & 58 & $\mathrm{M}$ & 1 & 2 & $\mathrm{E}$ & 2 & 0,6 & 2 & $1 \mathrm{a}$ \\
356 & 44 & $\mathrm{~F}$ & 2 & 3 & $\mathrm{~T}$ & 5 & 5 & 1 & $4 \mathrm{~b}$ \\
357 & 44 & $\mathrm{~F}$ & 1 & 2 & $\mathrm{~T}$ & 3 & 0,67 & 2 & $1 \mathrm{a}$ \\
360 & 78 & $\mathrm{~F}$ & 1 & 1 & $\mathrm{CP}$ & 3 & 2 & 2 & $2 \mathrm{a}$ \\
362 & 59 & $\mathrm{~F}$ & 1 & 1 & $\mathrm{CP}$ & 4 & 5,5 & 1 & $4 \mathrm{~b}$ \\
364 & 53 & $\mathrm{~F}$ & 1 & 2 & $\mathrm{E}$ & 4 & 2 & 1 & $2 \mathrm{~b}$ \\
\hline
\end{tabular}

Nota $\mathrm{N}=$ número do protocolo. Sexo, $\mathrm{M}=$ masculino $\mathrm{F}=$ feminino. Cor, 1 (Branca), 2 (Negra), 3 (Parda), 4 (Amarela). TC (Tipo de crescimento, 1 (LMM), 2 (MES), 3 (MN), 4 (MAL), 5 (Outros). Locali (Localização da lesão primaria), CP (Cabeça e pescoço), T (Tronco), E (Extremidades). Espessura de Breslow em milimetros. ULCER (Presença de ulceração), 1 (Sim), 2 (Não) pT= Estadiamento AJCC 2002. 
Anexo 2B - Variáveis demográficas, clínicas e histopatológicas de 74 casos de melanoma cutâneo com doença loco-regional na UMSC-SP 1993-2006.

\begin{tabular}{cccccccccc}
\hline$N$ & $I D A D E$ & SEXO & COR & TC & LOCALI & CLARK & BRESLOW & ULCER & $p T$ \\
\hline 1 & 22 & $\mathrm{M}$ & 2 & 3 & $\mathrm{CP}$ & 5 & 9,99 & 1 & $4 \mathrm{~b}$ \\
2 & 82 & $\mathrm{M}$ & 1 & 3 & $\mathrm{~T}$ & 5 & 5 & 2 & $4 \mathrm{a}$ \\
3 & 63 & $\mathrm{M}$ & 3 & 4 & $\mathrm{E}$ & 5 & 2 & - & - \\
4 & 46 & $\mathrm{M}$ & 1 & 3 & $\mathrm{E}$ & 5 & 5 & 2 & $4 \mathrm{a}$ \\
14 & 47 & $\mathrm{M}$ & 1 & 2 & $\mathrm{~T}$ & 4 & 1,4 & 2 & $2 \mathrm{a}$ \\
15 & 53 & $\mathrm{M}$ & 1 & 5 & $\mathrm{~T}$ & - & - & - & - \\
16 & 92 & $\mathrm{M}$ & 1 & 4 & $\mathrm{E}$ & 3 & 0,3 & 2 & $1 \mathrm{a}$ \\
18 & 57 & $\mathrm{M}$ & 1 & 2 & $\mathrm{~T}$ & 5 & 4 & 1 & $3 \mathrm{~b}$ \\
25 & 79 & $\mathrm{~F}$ & 1 & 5 & $\mathrm{E}$ & - & - & - & - \\
30 & 43 & $\mathrm{~F}$ & 1 & 2 & $\mathrm{E}$ & 3 & 8 & - & - \\
31 & 68 & $\mathrm{~F}$ & 1 & 4 & $\mathrm{E}$ & 3 & 3 & 1 & $3 \mathrm{~b}$ \\
38 & 63 & $\mathrm{M}$ & 1 & 3 & $\mathrm{~T}$ & 4 & 3 & 1 & $3 \mathrm{~b}$ \\
40 & 52 & $\mathrm{M}$ & 1 & 2 & $\mathrm{E}$ & 4 & 7 & 1 & $4 \mathrm{~b}$ \\
41 & 63 & $\mathrm{~F}$ & 1 & 4 & $\mathrm{E}$ & 5 & 10 & 2 & $4 \mathrm{a}$ \\
42 & 42 & $\mathrm{~F}$ & 1 & 3 & $\mathrm{~T}$ & 4 & 8 & 1 & $4 \mathrm{~b}$ \\
44 & 51 & $\mathrm{~F}$ & 1 & 1 & $\mathrm{CP}$ & 2 & 0,7 & 2 & $1 \mathrm{a}$ \\
45 & 74 & $\mathrm{~F}$ & 1 & 3 & $\mathrm{E}$ & 5 & 9,99 & 1 & $4 \mathrm{~b}$ \\
46 & 75 & $\mathrm{M}$ & 1 & 3 & $\mathrm{~T}$ & 3 & 3 & 2 & $3 \mathrm{a}$ \\
52 & 74 & $\mathrm{~F}$ & 1 & 4 & $\mathrm{E}$ & 3 & 1,5 & 2 & $2 \mathrm{a}$ \\
60 & 59 & $\mathrm{M}$ & 1 & 3 & $\mathrm{E}$ & - & - & - & - \\
66 & 94 & $\mathrm{~F}$ & 3 & 4 & $\mathrm{E}$ & 5 & 40 & 1 & $4 \mathrm{~b}$ \\
67 & 64 & $\mathrm{~F}$ & 1 & 3 & $\mathrm{CP}$ & 4 & 4 & 2 & $3 \mathrm{a}$ \\
69 & 55 & $\mathrm{~F}$ & 1 & 3 & $\mathrm{E}$ & 5 & 9 & 1 & $4 \mathrm{~b}$ \\
75 & 32 & $\mathrm{~F}$ & 1 & 2 & $\mathrm{E}$ & - & - & - & - \\
78 & 79 & $\mathrm{~F}$ & 1 & 3 & $\mathrm{CP}$ & 5 & 10 & 1 & $4 \mathrm{~b}$ \\
86 & 35 & $\mathrm{M}$ & 1 & 5 & - & - & - & - & - \\
93 & 41 & $\mathrm{M}$ & 1 & 3 & $\mathrm{E}$ & 4 & 7 & 1 & $4 \mathrm{~b}$ \\
95 & 42 & $\mathrm{~F}$ & 1 & 3 & $\mathrm{~T}$ & 5 & 5 & 1 & $4 \mathrm{~b}$ \\
97 & 64 & $\mathrm{M}$ & 1 & 3 & $\mathrm{E}$ & 4 & 5 & 2 & $4 \mathrm{a}$ \\
101 & 85 & $\mathrm{M}$ & 1 & 4 & $\mathrm{E}$ & 4 & 3 & 1 & $3 \mathrm{~b}$ \\
118 & 85 & $\mathrm{~F}$ & 3 & 4 & $\mathrm{E}$ & 5 & 2,2 & 1 & $3 \mathrm{~b}$ \\
123 & 43 & $\mathrm{M}$ & 1 & 2 & $\mathrm{~T}$ & 1 & - & 2 & - \\
149 & 77 & $\mathrm{~F}$ & 1 & 2 & $\mathrm{E}$ & 5 & 5 & 1 & $4 \mathrm{~b}$ \\
152 & 51 & $\mathrm{~F}$ & 1 & 4 & $\mathrm{E}$ & 5 & 2,3 & 1 & $3 \mathrm{~b}$ \\
154 & 61 & $\mathrm{M}$ & 1 & 2 & $\mathrm{~T}$ & 3 & 4 & 1 & $3 \mathrm{~b}$ \\
160 & 62 & $\mathrm{~F}$ & 1 & 4 & $\mathrm{E}$ & 5 & 10 & 1 & $4 \mathrm{~b}$ \\
166 & 69 & $\mathrm{M}$ & 1 & 4 & $\mathrm{E}$ & 5 & 4,5 & 1 & $4 \mathrm{~b}$ \\
167 & 51 & $\mathrm{M}$ & 1 & 3 & $\mathrm{E}$ & 5 & 14 & 1 & $4 \mathrm{~b}$ \\
168 & 75 & $\mathrm{~F}$ & 1 & 4 & $\mathrm{E}$ & 4 & 2,75 & 2 & $3 \mathrm{a}$ \\
170 & 52 & $\mathrm{~F}$ & 1 & 2 & $\mathrm{~T}$ & 3 & 2 & 2 & $2 \mathrm{a}$ \\
& & & & & & & & & $\mathrm{Continua}$
\end{tabular}


Conclusão: Anexo 2B - Variáveis demográficas, clínicas e histopatológicas de 74 casos de melanoma cutâneo com doença loco-regional na UMSC-SP 1993-2006.

\begin{tabular}{|c|c|c|c|c|c|c|c|c|c|}
\hline$N$ & $I D A D E$ & SEXO & $C O R$ & $T C$ & LOCALI & CLARK & BRESLOW & $\overline{U L C E R}$ & $\overline{p T}$ \\
\hline 172 & 46 & $\mathrm{~F}$ & 2 & 3 & $E$ & 3 & 6 & 2 & $4 a$ \\
\hline 178 & 74 & $\mathrm{~F}$ & 1 & 3 & $E$ & 4 & 20 & 1 & $4 b$ \\
\hline 182 & 68 & $F$ & 1 & 2 & $\mathrm{CP}$ & 4 & 7 & 2 & $4 a$ \\
\hline 184 & 92 & M & 1 & 3 & $\mathrm{CP}$ & 4 & 4 & 2 & $3 a$ \\
\hline 185 & 71 & $\mathrm{~F}$ & 1 & 4 & $E$ & 5 & 20 & 1 & $4 b$ \\
\hline 193 & 67 & $F$ & 1 & 4 & E & 4 & 4 & 1 & $3 b$ \\
\hline 199 & 44 & $\mathrm{~F}$ & 1 & 5 & $E$ & - & - & - & - \\
\hline 206 & 60 & M & 3 & 5 & - & - & - & - & - \\
\hline 214 & 57 & M & 1 & 2 & $E$ & 3 & 0,7 & 2 & $1 a$ \\
\hline 223 & 53 & M & 1 & 5 & $\mathrm{~T}$ & 3 & 2 & 2 & $2 a$ \\
\hline 225 & 64 & M & 3 & 4 & $E$ & 2 & 2 & 1 & $2 b$ \\
\hline 227 & 57 & $M$ & 3 & 5 & - & - & - & - & - \\
\hline 234 & 77 & $\mathrm{~F}$ & 3 & 4 & $E$ & 4 & 10 & 1 & $4 b$ \\
\hline 237 & 75 & $M$ & 1 & 2 & $\mathrm{~T}$ & 5 & 1,5 & 1 & $2 b$ \\
\hline 248 & 54 & $\mathrm{~F}$ & 2 & 4 & $E$ & 2 & 2 & 2 & $2 a$ \\
\hline 251 & 26 & $M$ & 1 & 3 & $\mathrm{~T}$ & 5 & 10 & 2 & $4 a$ \\
\hline 253 & 55 & $\mathrm{~F}$ & 3 & 3 & $E$ & 3 & 4 & 2 & $3 a$ \\
\hline 268 & 66 & $M$ & 1 & 2 & $\mathrm{~T}$ & 3 & 0,1 & 1 & $1 b$ \\
\hline 272 & 74 & $M$ & 1 & 5 & - & - & - & - & - \\
\hline 282 & 78 & $F$ & 1 & 5 & - & - & - & - & - \\
\hline 288 & 70 & $F$ & 1 & 4 & $E$ & 5 & 9 & 1 & $4 b$ \\
\hline 304 & 72 & $F$ & 1 & 3 & $E$ & 5 & 14 & 1 & $4 b$ \\
\hline 309 & 73 & $F$ & 1 & 2 & $\mathrm{~T}$ & 4 & 5 & 1 & $4 b$ \\
\hline 310 & 30 & $M$ & 1 & 2 & $E$ & 3 & 6 & - & - \\
\hline 311 & 48 & $F$ & 1 & 3 & $E$ & 3 & 0,5 & 1 & $1 b$ \\
\hline 313 & 40 & $M$ & 1 & 3 & $E$ & 3 & 10 & 1 & $4 b$ \\
\hline 314 & 59 & $M$ & 1 & 3 & $\mathrm{~T}$ & 3 & 15 & 1 & $4 b$ \\
\hline 321 & 12 & $M$ & 1 & 3 & $E$ & 4 & 16 & 1 & $4 b$ \\
\hline 322 & 65 & $F$ & 1 & 3 & $\mathrm{~T}$ & 3 & 3 & 1 & $3 b$ \\
\hline 324 & 50 & $M$ & 1 & 3 & $\mathrm{~T}$ & 5 & 10 & 1 & $4 b$ \\
\hline 340 & 78 & $M$ & 1 & 3 & E & - & - & - & - \\
\hline 345 & 57 & $M$ & 1 & 5 & $\mathrm{~T}$ & - & - & - & - \\
\hline 359 & 74 & $F$ & 3 & 3 & E & 5 & 10 & - & - \\
\hline 365 & 81 & $M$ & 1 & 3 & $E$ & 5 & 10 & - & - \\
\hline
\end{tabular}

Nota $\mathrm{N}=$ número do protocolo. Sexo $\mathrm{M}$ (masculino), $\mathrm{F}$ (feminino). Cor 1 (Branca), 2 (Negra), 3 (Parda), 4 (Amarela). TC (Tipo de crescimento) 1 (LMM), 2 (MES), 3 (MN), 4( MAL). Locali (Localização da lesão primária), CP (Cabeça e pescoço), T (Tronco), E (Extremidades). Espessura de Breslow em milímetros. ULCER, (Presença de ulceração), 1 (Sim), 2 (Não) pT = Estadiamento AJCC 2002. 
Anexos 80

Anexo 2C - Variáveis demográficas, clínicas e histológicas de 33 casos de melanoma cutâneo com doença sistêmica na UMSC-SP 1993-2006.

\begin{tabular}{|c|c|c|c|c|c|c|c|c|c|}
\hline$N$ & IDADE & SEXO & COR & $T C$ & $\angle O C A L I$ & CLARK & BRESLOW & ULCER & $p T$ \\
\hline 5 & 53 & $F$ & 1 & 4 & $E$ & 3 & 1,5 & 2 & $2 a$ \\
\hline 21 & 70 & $\mathrm{~F}$ & 1 & 5 & E & - & - & - & - \\
\hline 24 & 57 & $\mathrm{~F}$ & 1 & 5 & $\mathrm{~T}$ & - & 4,1 & - & - \\
\hline 26 & 69 & $M$ & 1 & 5 & - & - & - & - & - \\
\hline 28 & 68 & $M$ & 1 & 5 & $\mathrm{~T}$ & - & - & - & - \\
\hline 32 & 24 & $M$ & 1 & 2 & $\mathrm{~T}$ & 2 & 0,7 & 2 & $1 a$ \\
\hline 36 & 31 & $\mathrm{~F}$ & 1 & 3 & $\mathrm{~T}$ & 4 & 8 & 2 & $4 a$ \\
\hline 48 & 69 & $\mathrm{~F}$ & 1 & 4 & $E$ & 5 & 4,5 & 2 & $4 a$ \\
\hline 73 & 70 & $M$ & 1 & 3 & $\mathrm{CP}$ & 5 & 6,2 & 2 & $4 a$ \\
\hline 84 & 52 & $M$ & 1 & 3 & $\mathrm{CP}$ & 5 & 5 & 1 & $4 b$ \\
\hline 89 & 30 & $M$ & 1 & 3 & $\mathrm{~T}$ & 4 & 8 & 1 & $4 b$ \\
\hline 94 & 40 & $\mathrm{~F}$ & 1 & 3 & - & 5 & 5 & 2 & $4 a$ \\
\hline 99 & 35 & $\mathrm{~F}$ & 1 & 3 & $\mathrm{~T}$ & 2 & 0,7 & 2 & $1 a$ \\
\hline 117 & 52 & $M$ & 3 & 4 & $E$ & 4 & 5 & 2 & $4 a$ \\
\hline 134 & 83 & $M$ & 3 & 4 & $E$ & 5 & 10 & 1 & $4 b$ \\
\hline 147 & 43 & $F$ & 3 & 4 & $E$ & 4 & 5 & 2 & $4 a$ \\
\hline 192 & 76 & $F$ & 1 & 5 & - & - & - & - & - \\
\hline 207 & 36 & $M$ & 1 & 5 & $E$ & 5 & 25 & 1 & $4 b$ \\
\hline 220 & 61 & $M$ & 3 & 5 & - & - & - & - & - \\
\hline 226 & 55 & $M$ & 1 & 2 & $\mathrm{~T}$ & 5 & 10 & 1 & $4 b$ \\
\hline 236 & 53 & $F$ & 1 & 5 & $\mathrm{~T}$ & - & - & - & - \\
\hline 260 & 53 & $F$ & 1 & 3 & $\mathrm{~T}$ & 3 & 2,2 & 2 & $3 a$ \\
\hline 271 & 66 & $F$ & 1 & 3 & E & 5 & 4 & 2 & $3 a$ \\
\hline 278 & 49 & $M$ & 1 & 3 & - & 3 & 7 & 1 & $4 b$ \\
\hline 281 & 62 & $F$ & 1 & 5 & - & - & - & - & - \\
\hline 284 & 55 & $M$ & 1 & 3 & $\mathrm{~T}$ & 5 & 10 & 1 & $4 b$ \\
\hline 298 & 20 & $M$ & 1 & 5 & $\mathrm{CP}$ & - & - & - & - \\
\hline 334 & 59 & $M$ & 1 & 4 & $E$ & 5 & 10 & - & - \\
\hline 337 & 61 & $M$ & 1 & 5 & $\mathrm{CP}$ & - & - & - & - \\
\hline 343 & 66 & $M$ & 1 & 3 & $\mathrm{~T}$ & 5 & 10 & 1 & $4 b$ \\
\hline 348 & 32 & $F$ & 1 & 2 & $\mathrm{CP}$ & 5 & 4 & 2 & $3 a$ \\
\hline 350 & 85 & $M$ & 1 & 2 & $\mathrm{~T}$ & 1 & - & 2 & - \\
\hline 361 & 74 & $\mathrm{~F}$ & 4 & 4 & $E$ & 2 & 0,7 & - & - \\
\hline
\end{tabular}
de ulceração), 1 (Sim), 2 (Não) pT=Estadiamento AJCC 2002. 
Anexo 3 - Estadiamento do melanoma cutâneo da American Joint Committee on Cancer de 2002.

\section{CLASSIFICAÇÃO TNM DO MELANOMA}

\begin{tabular}{|c|c|c|c|c|}
\hline$T$ & ESPESSURA & \multicolumn{3}{|c|}{ ULCERAÇÃO } \\
\hline T1 & $=1,0 \mathrm{~mm}$ & \multicolumn{2}{|c|}{$\begin{array}{l}\text { a: ausência de ulceração e nível II / } \\
\text { III }\end{array}$} & $\begin{array}{l}\text { b: com ulceração } \\
\text { ou nível IV / V }\end{array}$ \\
\hline $\mathrm{T} 2$ & $1,01-2,0 \mathrm{~mm}$ & \multicolumn{2}{|c|}{ a: ausência de ulceração } & b: com ulceração \\
\hline T3 & $2,01-4,0 \mathrm{~mm}$ & \multicolumn{2}{|c|}{ a: ausência de ulceração } & b: com ulceração \\
\hline T4 & $>4,0 \mathrm{~mm}$ & \multicolumn{2}{|c|}{ a: ausência de ulceração } & b: com ulceração \\
\hline $\mathrm{N}$ & \multicolumn{2}{|c|}{ № LN Metastáticos } & \multicolumn{2}{|c|}{ Infiltração Tumoral } \\
\hline NI & \multicolumn{2}{|l|}{1 Linfonodo } & \multicolumn{2}{|c|}{$\begin{array}{l}\text { a: micrometástase* } \\
\text { b: macrometástase** }\end{array}$} \\
\hline N2 & \multicolumn{2}{|l|}{ 2-3 Linfonodos } & \multicolumn{2}{|c|}{$\begin{array}{l}\text { a: micrometástase* } \\
\text { b: macrometástase** } \\
\text { c: metástase em trânsito / satelitoses / } \\
\text { sem metástases linfonodais }\end{array}$} \\
\hline N3 & \multicolumn{2}{|c|}{$\begin{array}{l}4 \text { ou mais linfonodos } \\
\text { metastáticos, ou linfonodos } \\
\text { confluentes, ou metástases em } \\
\text { trânsito / satelitoses com } \\
\text { linfonofos metastáticos }\end{array}$} & & \\
\hline \multicolumn{5}{|c|}{$\begin{array}{l}\text { * micrometástases são diagnosticadas após pesquisa de linfonodo sentinela ou } \\
\text { linfadenectomia eletiva. } \\
\text { ** macrometástases são definidas como metástases em linfonodo, clinicamente } \\
\text { detectável, confirmado por linfadenectomia terapêutica ou quando a metástase } \\
\text { linfonodal exibe extensão extracapsular macroscópica. }\end{array}$} \\
\hline M1 & \multicolumn{3}{|l|}{ LOCALIZAÇÃO } & DHL NO SORO \\
\hline M1a & \multicolumn{3}{|c|}{$\begin{array}{l}\text { Metástase cutânea, subcutânea ou linfonodal à } \\
\text { distância. }\end{array}$} & normal \\
\hline M1b & \multicolumn{3}{|c|}{ Metástase em pulmão } & normal \\
\hline M1c & \multicolumn{3}{|c|}{$\begin{array}{l}\text { Metástases em outras vísceras } \\
\text { Qualquer metástase à distância }\end{array}$} & $\begin{array}{l}\text { normal } \\
\text { elevado }\end{array}$ \\
\hline
\end{tabular}




\section{AGRUPAMENTO NOS ESTÁDIOS}

\begin{tabular}{|c|c|c|c|c|c|c|c|}
\hline \multicolumn{4}{|c|}{ Estadiamento clínico* } & \multicolumn{4}{|c|}{ Estadiamento patológico+ } \\
\hline & $\mathbf{T}$ & $\mathbf{N}$ & $\mathbf{M}$ & & $\mathbf{T}$ & $\mathbf{N}$ & $\mathbf{M}$ \\
\hline $\mathbf{0}$ & Tis & NO & MO & $\mathbf{0}$ & Tis & NO & MO \\
\hline IA & T1a & NO & MO & IA & T1a & NO & MO \\
\hline \multirow[t]{2}{*}{ IB } & T1b & NO & MO & IB & T1b & NO & MO \\
\hline & $\mathrm{T} 2 \mathrm{a}$ & NO & MO & & $\mathrm{T} 2 \mathrm{a}$ & NO & MO \\
\hline \multirow[t]{2}{*}{ IIA } & $\mathrm{T} 2 \mathrm{~b}$ & NO & MO & IIA & $\mathrm{T} 2 \mathrm{~b}$ & NO & MO \\
\hline & T3a & NO & MO & & T3a & NO & MO \\
\hline \multirow[t]{2}{*}{ IIB } & T3b & NO & MO & IIB & T3b & NO & M0 \\
\hline & $\mathrm{T} 4 \mathrm{a}$ & NO & MO & & T4a & NO & MO \\
\hline IIC & T4b & NO & MO & IIC & T4b & NO & MO \\
\hline \multirow[t]{3}{*}{ III } & qqT & N1 & MO & III & & & \\
\hline & & N2 & & & & & \\
\hline & & N3 & & & & & \\
\hline \multirow[t]{2}{*}{ IIIA } & & & & IIIA & T1-4a & $\mathrm{N} 1 \mathrm{a}$ & MO \\
\hline & & & & & T1-4a & $\mathrm{N} 2 \mathrm{a}$ & MO \\
\hline \multirow[t]{5}{*}{ IIIB } & & & & IIIB & T1 -4b & $\mathrm{N} 1 \mathrm{a}$ & MO \\
\hline & & & & & $\mathrm{T} 1-4 \mathrm{~b}$ & $\mathrm{~N} 2 \mathrm{a}$ & MO \\
\hline & & & & & $\mathrm{T} 1-4 \mathrm{a}$ & N1b & MO \\
\hline & & & & & T1-4a & $\mathrm{N} 2 \mathrm{~b}$ & MO \\
\hline & & & & & $\mathrm{T} 1-4 \mathrm{a} / \mathrm{b}$ & $\mathrm{N} 2 \mathrm{C}$ & MO \\
\hline \multirow[t]{3}{*}{ IIIC } & & & & IIIC & $T 1-4 b$ & N1b & MO \\
\hline & & & & & $T 1-4 b$ & $\mathrm{~N} 2 \mathrm{~b}$ & MO \\
\hline & & & & & $\mathrm{qqT}$ & N3 & MO \\
\hline IV & qqT & qqN & qqM1 & IV & qqT & qqN & qqM1 \\
\hline
\end{tabular}

*Estadiamento clínico inclui microestadiamento do melanoma primário e avaliação clínica e radiológica para metástases. Por convenção deve ser usado após a completa excisão do melanoma primário, com avaliação clínica das metástases regionais e à distância.

+Estadiamento patológico inclui microestadiamento do melanoma primário e informações patológicas a respeito dos linfonodos regionais após linfadenectomia parcial ou completa. Pacientes com estádio patológico 0 ou IA são a exceção; eles não requerem avaliação patológica de seus linfonodos. 
REFERÊNCIAS BIBLIOGRÁFICAS* 
American Joint Committee on Cancer (AJCC). Edited by Greene FL, Page DL, Fleming ID, Fritz AG, Bach C, Halleer DG, et al. Cancer staging manual. $6^{\text {th }}$ ed. New York: Springer-Verlag; 2002.

Australian Institute of Health and Welfare (AIHW), Australasian Association of Cancer Registries (AACR). Cancer in Australia 1997: Incidence and mortality data for 1997 and selected data for 1998 and 1999.AIHW cat. no. CAN 10. Canberra, Australia: AIHW; 2000. (Cancer Series, no 15)

Armstrong BK, Kricker A. Cutaneous melanoma. Cancer Surv. 1994; 19:219-40.

Bakos L. Melanomas malignos e etnia. An Bras Dermatol. 1991; 66: 299-302.

Bakos L, Gleiser AL, Dziekaniak K, Leite CM, Pisani AC, Duarte R, et al. Sol e melanomas: fatores de risco na população branca riograndense. An Bras Dermatol. 1998; 73 (Supl1): 6-11.

Bakos L, Wagner M, Bakos RM, Leite CS, Sperhacke CL, Dzekaniak $\mathrm{KS}$, et al. Sunburn, sunscreens and phenotypes: some risk factors for cutaneous melanoma in southern Brazil. Int J Dermatol. 2002; 41:557-62.

Balch, CM, Buzaid AC, Soong SJ, Atkins MB, Cascinelli N, Coit DG, et al. Final version of the American Joint Committee on Cancer Staging System for Cutaneous Melanoma. J Clin Oncol. 2001a; 19:3635-48.

Balch CM, Murad TM, Soong SJ, Ingalls AL, Halpern NB, Maddox WA. A multifactorial analysis of melanoma: prognostic histopathological features comparing Clark's and Breslow's staging methods. Ann Surg. $1978 ; 188: 732-42$.

Balch CM, Soong SJ, Gershenwald JE, Thompson JF, Reintgen DS, Cascinelli $N$, et al. Prognostic factors analysis of 17,600 melanoma patients: validation of the American Joint Committee on Cancer melanoma staging system. J Clin Oncol. 2001b; 19:3622-34.

Bandiera DC, Prudente A. Melanoma maligno. In: Roxo Nobre MO, Junqueira ACC. Cancerologia prática. São Paulo: Fundo Editorial Procienx; 1967. v.1, p.228-40. 
Barth A, Wanek LA, Morton DL. Prognostic factors in 1512 melanoma patients with distant metastases. J Am Coll Surg. 1995; 181:193-201.

Bernardi CDV, Favaretto AL, Brancher MC, Ponzio HA. Freqüência de Melanoma maligno no Serviço de Dermatologia da ISCMPA/UFRGS. An Bras Dermatol. 1998; 73 (Supl 1): 6-11.

Brandão M, Filardi F, Domenech J, Acioli J, Noya M, Sampaio C, et al. Melanoma cutâneo: descrição de 76 casos. Grupo Brasileiro de Melanoma. Boletim Informativo do GBM 1998; 1(1): 2.

Buettner PG, Leiter U, Eigentler TK, Garbe C. Development of prognostic factors and survival in cutaneous melanoma over 25 years: an analysis of the Central Malignant Melanoma Registry of the German Dermatological Society. Cancer. 2005; 103: 616-24.

Bulliard JL, Cox B. Cutaneous malignant melanoma in New Zealand: trends by anatomic site, 1969-1993. Int J Epidemiol. 2000; 29:41623.

Bulliard JL, Cox B, Semenciw R. Trends by anatomic site in the incidence of cutaneous malignant melanoma in Canada, 1969-93. Cancer Causes Control. 1999; 10:407-16.

Chang AE, Karnell LH, Menck HR. The National Cancer Data Base report on cutaneous and noncutaneous melanoma. A summary of 84.836 cases from the past decade. The American College of Surgeons Commission on Cancer and the American Cancer Society. Cancer.1998; 83:1664-78.

Clark WH Jr, From L, Bernardino EA, Mihm MC. The histogenesis and biologic behavior of primary human malignant melanomas of the skin. Cancer Res. 1969; 29:705-27.

Cohen LM. Lentigo maligna and lentigo maligna melanoma. J Am Acad Dermatol. 1995; 33:923-37.

Criado PR, Vasconcellos C, Sittart JA, Valente, NY, Moura BP, Barbosa $\mathrm{GL}$, et al. Melanoma maligno cutâneo primário: estudo retrospectivo de 1963 a 1997 no Hospital do Servidor Público Estadual de São Paulo. Rev Assoc Méd Bras. 1999; 45: 157-62. 
Dennis LK. Analysis of the melanoma epidemic, both apparent and real: Data from 1973 through 1994 Surveillance, Epidemiology and end Results, Program Registry. Arch Dermatol. 1999; 135:275-80.

Dick OW, Santos MLR, Santos FAR, Frischenbruder JA, Costa PG, Rocha VHB. Melanoma maligno: idade X estadiamento clínico: estudo retrospectivo de 161 casos. An Bras Dermatol. 1989; 64:151-3.

Donato CA, Yokomizo V, Peres Rosa I. Melanoma maligno: avaliação de 58 casos em um período de 11 anos (jan. / 85- dez. / 95). Med Cut Iber Lat Am. 1997; 25:265-9.

Eigentler TK, Buettner PG, Leiter U, Garbe C. Central Malignant Melanoma Registry of the German Dermatological Society. Impact of ulceration in stages I to III cutaneous melanoma as staged by the American Joint Committee on Câncer Staging System: an analysis of the German Central Malignant Melanoma Registry. J Clin Oncol. 2004; 22: 4376-83.

Fernandes NC, Calmon R, Maceira JP, Cuzzi T, Silva CSC. Melanoma cutâneo: estudo prospectivo de 65 casos. An Bras Dermatol. 2005; $80: 25-34$.

Fernandes NC, Cardoso ICL, Maceira J, Perez M. Melanoma: estudo retrospectivo de 47 casos. An Bras Dermatol. 1996; 71:381-5.

Garbe C, McLeod GR, Buettner PG. Time trends of cutaneous melanoma in Queensland, Australia and Central Europe. Cancer. 2000; 89:1269-78.

Giavina-Bianchi MH, Festa Neto C, Sanches Jr JA, Golcman B, Golcman R, Sotto MN, et al. Análise de 115 casos de melanoma. Jornal Dermatológico da SBD-RESP. 1996; Ano XI (74): 4-5.

Giles GG, Armstrong BK, Burton RC, Staples MP, Thursfield VJ. Has mortality from melanoma stopped rising in Australia? Analysis of trends between 1931 and 1994. BMJ. 1996; 312:1121-5.

Gon AS, Minelli L, Guembarovski AL. Melanoma cutâneo primário em Londrina. An Bras Dermatol. 2001; 76:413-26. 
Instituto Brasileiro de Geografia e Estatística (IBGE). Censo 2000. [Internet] [citado em 13 de março de 2006] Disponível em: http://www.ibge.gov.br

International Union Against Cancer (UICC).Edited by Parkin DM, Whelan SL, Ferlay J, Raymond L, Young J. Cancer incidence in five continents. Lyon, France: IARC; 1997. v. 7. (Scientific Publication, no 143)

Jemal A, Devesa SS, Hartge P, Tucker MA. Recent trends in cutaneous melanoma incidence in the United States. J Natl Cancer Inst. 2001; 93:678-83.

Lapa MS, Guedes KF, Schalch FO, Landman G. Melanomas malignos cutâneos tratados no Hospital de Câncer de São Paulo. Estudo retrospectivo para avaliação de distribuição, fatores prognósticos e sobrevida. An Bras Dermatol. 2002; 77:313-20.

Lee JA. The systematic relationship between melanomas diagnosed in situ and when invasive. Melanoma Res. 2001; 11:523-9.

Lipsker DM, Hedelin G, Heid E, Grosshans EM, Cribier BJ. Striking increase of thin melanomas contrasts with stable incidence of thick melanomas. Arch Dermatol. 1999; 135:1451-6.

Lucas EA, Deps PD, Lima JGB, Toribio R, Gomes CC. Melanoma maligno: estudo casuístico retrospectivo de 1982 a 1992, no Hospital Universitário da UFES. Arq Bras Med. 1994; 68:67-70.

MacKie RM, Aitchison T, Sirel JM, McLaren K, Watt DC. Prognostic models for subgroups of melanoma patients from the Scottish Melanoma Group database 1979-86, and their subsequent validation. Br J Cancer. 1995, 71:173-6.

Marrett LD, Nguyen HL, Armstrong BK. Trends in the incidence of cutaneous malignant melanoma in New South Wales, 1983-1996. Int J Cancer. 2001; 92:457-62.

Marghoob AA, Koenig K, Bittencourt FV, Kopf AW, Bart RS. Breslow thickness and Clarck level in melanoma: support for including level in pathology reports and in American Joint Committee on Cancer Staging. Cancer. 2000; 88:589-96. 
Minelli L, Pereira VL. Melanoma: estudo casuístico do Instituto do Câncer de Londrina. An Bras Dermatol. 1983; 58: 81-4.

Moreno M. Perfil dos pacientes com melanoma cutâneo no oeste de Santa Catarina, Brasil. Grupo Brasileiro de Melanoma. Boletim Informativo do GBM 2005; Ano VIII, $\mathrm{N}^{\circ}$ 30. p.3

Morton DL, Davtyan DG, Wanek LA, Foshag LJ, Cochran AJ. Multivariate analysis of the relationship between survival and the microstage of primary melanoma by Clark level and Breslow thickness. Cancer. 1993; 71:3737-43.

Nasser N. Epidemiologia do melanoma maligno em Blumenau-SC. An Bras Dermatol. 1993; 68: 17-20.

Parker SL, Tong T, Bolden S, Wingo PA. Cancer statistics. CA Cancer J Clin. 1996 46:5-27.

Parkin DM, Bray F, Ferlay J, Pisani P. Global Cancer statistics, 2002 CA. Cancer J Clin. 2005; 55:74-108.

Pinheiro AMCF, Cabral H, Rodrigues ALSV, Abe H. Melanoma cutâneo: características clínicas, epidemiológicas e histopatológicas no Hospital Universitário de Brasília entre Janeiro de 1994 e Abril de 1999. An Bras Dermatol. 2003; 78: 179-86.

Reintgen DS, McCarty KM Jr, Cox E, Seigler HF. Malignant melanoma in black American and white American populations. A comparative review. JAMA. 1982; 248:1856-9.

Retsas S, Henry K, Mohammed MQ, MacRae K. Prognostic factors of cutaneous melanoma and a new staging system proposed by the American Joint Committee on Cancer (AJCC): validation in a cohort of 1284 patients. Eur J Cancer. 2002; 38:511-6.

Seiji M, Takahashi M. Acral melanoma in Japan. Hum Pathol. 1982; 13:607-9.

Slingluff CL Jr, Vollmer R, Seigler HF. Acral melanoma: A review of 185 patients with identification of prognostic variables. J Surg Oncol. 1990; 45:91-8. 
Schultz S, Kane M, Roush R, Miller V, Berd D, Goldman L, et al. Time to recurrence varies inversely with thickness in clinical stage I cutaneous melanoma. Surg Gynecol Obstet. 1990; 171:393-7.

Sober AJ, Tsao $\mathrm{H}$. Acquired precursor lesions and markers of increased risk for cutaneous melanoma. In: Balch CM, Houghton AN, Sober AJ, Soong S. Cutaneous melanoma. $4^{\text {th }}$ ed. Saint Louis, Missouri: Q uality Medical Publishing; 2003. p 122.

Surveillance, Epidemiology, and End Results (SEER) Program, Public Use Data (1973-1999). National Cancer Institute, DCCPS, Surveillance Research Program. Cancer Statistics Branch, 2002. [ cited 2006 jan 14] Avaiable from:URL: http: /www.seer.cancer.gov

van der Esch EP, Cascinelli N, Preda F, Morabito A, Bufalino R. Stage I melanoma of the skin: evaluation of prognosis according to histologic characteristics. Cancer. 1981; 48:1668-73.

van der Rhee $H J$, van der Spek-keijser LM, van Westering $R$, Coebergh JW. Increase in and stabilization of incidence and mortality of primary cutaneous malignant melanoma in Western Netherlands, 1980-95. Br J Dermatol. 1999; 140:463-7.

Venegas LFP, Flores C, Blacher GG, Daudt AW, Cerski CTS. Melanoma maligno cutâneo no Rio Grande do Sul: estudo de 101 casos. Rev Assoc Med Bras. 1992; 38:122-6.

Weinstock MA, Berwick M. Epidemiology: Current Trends. In: Balch CM, Houghton AN, Sober AJ, Soong S. Cutaneous melanoma, $4^{\text {th }}$ ed. Saint Louis, Missouri: Quality Medical Publishing; 2003. p 18.

Weinstock MA, Mikkilinemi R. Epidemiology. In: Sober AJ, Haluska FG, editors. Skin cancer. London: BC Decker; 2001. p. 1-15. (American Cancer Society Atlas of Clinical Oncology)

Weinstock MA, Sober AJ. The risk of progression of lentigo maligna to lentigo maligna melanoma. $\mathrm{Br} J$ Dermatol. 1987; 116:303-10.

*De acordo com:

Adaptado de Internacional Committee of Medical Journals Editors (Vancouver). 
Universidade de São Paulo. Faculdade de Medicina. Serviço de Biblioteca e Documentação. Guia de apresentação de dissertações, teses e monografias da FMUSP. Elaborado por Anneliese Carneiro da Cunha, Maria Julia A.L. Freddi, Maria F. Crestana, Marinalva de S. Aragão, Suely C. Cardoso, Valéria Vilhena. $2^{a}$ ed. São Paulo: Serviço de Biblioteca e Documentação; 2005.

Abreviaturas dos títulos dos periódicos de acordo com List of Journals Indexed in Index Medicus. 
BIBLIOGRAFIA CONSULTADA 
Balch CM, Houghton AN, Sober AJ, Soong S. Cutaneous melanoma, $4^{\text {th }}$ ed. Saint Louis, Missouri: Quality Medical Publishing; 2003.

Sober AJ, Haluska FG. Skin Cancer. London: BC Decker Inc. 2001; 115. 